Research Article

\title{
Design and Performance of Concrete Pile Strengthened with Lengthened Steel-Tube Core: Model Tests and Numerical Simulations
}

\author{
Shangyu Han (iD) and Lei Yun (iD) \\ College of Civil Engineering and Architecture, Nanchang Hangkong University, Nanchang 330063, China \\ Correspondence should be addressed to Shangyu Han; hshyu@nchu.edu.cn
}

Received 10 February 2021; Revised 7 April 2021; Accepted 16 April 2021; Published 24 April 2021

Academic Editor: Wangcheng Zhang

Copyright (C) 2021 Shangyu Han and Lei Yun. This is an open access article distributed under the Creative Commons Attribution License, which permits unrestricted use, distribution, and reproduction in any medium, provided the original work is properly cited.

\begin{abstract}
In order to solve the problem of insufficient bearing capacity of existing concrete piles, a type of concrete pile with an additional lengthened strengthening core is designed, by inserting the steel tube through guiding hole and pouring core concrete. To reveal the mechanical performance of the reinforced piles, scale model tests and finite element simulations were performed. The results showed that both the vertical and horizontal bearing capacity increase with the length of the stiffening core. The axial force of the enhanced core is also smaller than conventional concrete piles, and the extended core can share the axial force of the foundation pile to improve the stress distribution of the pile body. These findings point toward a useful and general method for increasing the load capacity of existing concrete piles.
\end{abstract}

\section{Introduction}

Due to the characteristics of high bearing capacity, reliable construction quality, and wide range of application, concrete filling piles have been widely used in all kinds of new construction and reconstruction projects. However, because of many uncontrollable factors (such as soft soil around the pile, concrete segregation, and sediment at the bottom of the pile), engineering problems such as pile defects, insufficient bearing capacity, and even broken pile are inevitable, which have a negative impact on the bearing capacity and construction efficiency of the foundation pile to a certain extent.

For concrete piles with inadequate performances (for example, piles with slight defects such as concrete segregation and local necking; piles with obvious defects such as cracking and excessive sediment), the academic and engineering circles have made many efforts on the defect detection methods, reinforcement theories, and technologies. Psychas et al. [1] combined the finite element method (FEM), the scaled boundary FEM, and ant colony classification algorithm to identify the flaws in piles. Wu et al. [2-4] theoretically investigated the response of an extended defective pile shaft-supporting superstructure. Kim et al. [5, 6] obtained the required axial stiffness of reinforcing pile in vertical extension remodeling to strengthen the existing defective piles with the 3D FEM. Neto et al. [7] reported the load capacity of bored piles with a structural defect in a deep foundation through both experimental and numerical approaches. Wang et al. [8] considered the lateral monotonic and cyclic performance of cast in situ piles with jet-grouting reinforcement in soft soils through a field study. Li et al. [9] inspected the lateral bearing capacity of postgrouting superlong bored piles by on-site tests. Dai and Wan [10] analytically presented the load transfer features and settlement computation method of postgrouting piles. Lin et al. $[11,12]$ tested the axial compression and pullout response of biogrouting enhanced pervious concrete piles. Ren et al. [13] examined the vertical bearing capacity of jet-groutpile-strengthened piles with expanded cross sections. Ozden and Akdag $[14,15]$ executed model tests on the conventional reinforced concrete (RC) piles enforced by steel fiberreinforced concrete. Sen et al. $[16,17]$ performed 
experimental study to analyze the effect of fiber-reinforced polymers (FRPs) in the repair of corroded piles. Ali et al. [18] used the nonlinear FEM and experimental method to evaluate the shear capacity of RC piles reinforced with steel and FRP bars. Chaallal et al. [19] focused on the design and application of carbon fiber-reinforced polymers (CFRPs) in the repair and reinforcement of prestressed deficient piles under marine environment. Lin et al. [20] studied the behaviors of corroded CFRP-repaired prestressed concrete piles in landing stage structures through reduced-scale tests and finite element modeling. Rambo-Roddenberry et al. [21] tested the mechanical behaviors of the CFRP prestressed concrete piles for bridge foundations. Zhuang et al. [22] explored the reinforcement-corrosion-induced cracking behavior of CFRP strengthened reinforced RC piles in a marine environment. $\mathrm{Wu}$ et al. [23] proposed and experimentally investigated the behavior of hybrid glass fiber-reinforced polymer (GFRP) and steel bars reinforced prestressed high-strength concrete piles. Murugan et al. $[24,25]$ carried out experimental studies on the properties of CFRP and GFRP strengthened RC piles under static and cyclic lateral loadings.

The above research work or treatment measures are helpful to improve the bearing capacity of RC piles and can be used to solve the quality problems of slightly defective piles and some obviously defective piles. However, for obvious defective piles and seriously defective piles (e.g., complete fracture of pile body and insufficient pile length) in engineering projects with strict quality requirements (such as in high-grade highway projects), and the old defective piles in the reconstruction and expansion projects, the applicability of existing technology will be limited to a certain degree. At present, these heavily defective piles are usually treated by in situ rework or additional piling, which not only increases the cost of foundation pile construction but also raises the risk of engineering construction and even causes design changes, which seriously affects the progress, benefit, and construction environment of the related engineering projects.

In view of this, in order to improve the retention ratio of concrete piles with obvious and serious defects in new projects, as well as old concrete piles in reconstruction and expansion projects, it is necessary to carry out further research on the treatment technology, so as to solve the two key problems, i.e., the retaining of existing concrete piles and improvement of the bearing capacity of pile body. Considering the key factors of these two problems, this paper proposes a new type of concrete pile structure with lengthened strengthening core. Different from the existing technologies, through piloting hole in the pile core, this new foundation pile structure is formed by concrete pile and a lengthened strengthening core whose length is larger than the pile. On the basis of expounding the basic form of the structure, this paper studies the bearing capacity of the proposed pile structure through reduced-scale model tests and numerical simulations.

The remaining of this paper is organized as follows. In Section 2, an introduction to the new foundation pile is presented. Following, details about the scale model tests are reported in Section 3. Next in Section 4, finite element simulations in close accordance with experiment work are carried out to further reveal the performance of the proposed pile. Finally, conclusions are made in Section 5.

\section{Structural Design of Concrete Pile with Enhanced Core}

Considering that the bearing capacity of concrete pile is obviously affected by the pile length, the pile diameter is usually large, and there is no reinforcement in the pile core, this paper puts forward a kind of lengthened-core pile structure to improve the bearing capacity of conventional piles. As shown in Figure 1, this new structure mainly consists of concrete pile and lengthened core-concrete-filled steel pipe. Generally, there are three crucial issues in the design and manufacture of this structure, namely, holeguiding in the concrete pile, preparation of steel tube, and the pouring of core concrete into the steel tube.

2.1. Hole-Guiding. Because the diameter of the existing pile is usually more than $600 \mathrm{~mm}$ in practical engineering, a hole with a diameter of no less than $300 \mathrm{~mm}$ can be drilled, according to the bearing demand. The hole-guiding equipment should be vertically placed, and the drilling depth should reach the length of the steel tube. Besides, in the holeguiding process (see Figure 2 for a sketch), disturbance to the existing concrete pile and the soil around the pile should be minimized.

2.2. Steel Pipe. As the carrier of the existing pile to achieve the enhanced ability, the steel pipe should be designed to facilitate the pouring of core concrete and to ensure that the new and old concrete interfaces have no relative dislocation. Based on these considerations, the length of the steel tube should equal the total length of the reinforced pile, and the pipe diameter should be slightly smaller than the diameter of the guiding hole. In addition, the sidewall of the steel pipe should contain a number of seepage holes to guarantee the firm bond between the new and old concrete. Accordingly, circular steel pipe of total length $L+l$, external diameter $D$, and thickness $t$ is adopted, as shown in Figure 1.

2.3. Core Concrete in the Steel Pipe. The strengthened core concrete in the steel tube should not be weaker than the existing pile. Besides, it should have greater fluidity. Selfcompacting concrete or grouting material concrete can be used. A pouring pipe is adopted to pour the concrete from the bottom to the top of steel tube. After the concrete pouring in the steel tube is completed, cement paste should be grouted outside the steel pipe to improve the integrity of the structure.

\section{Model Test of the Strengthened Pile}

In this section, we mainly focus on the vertical and horizontal mechanical behaviors (e.g., the bearing capacity) of 


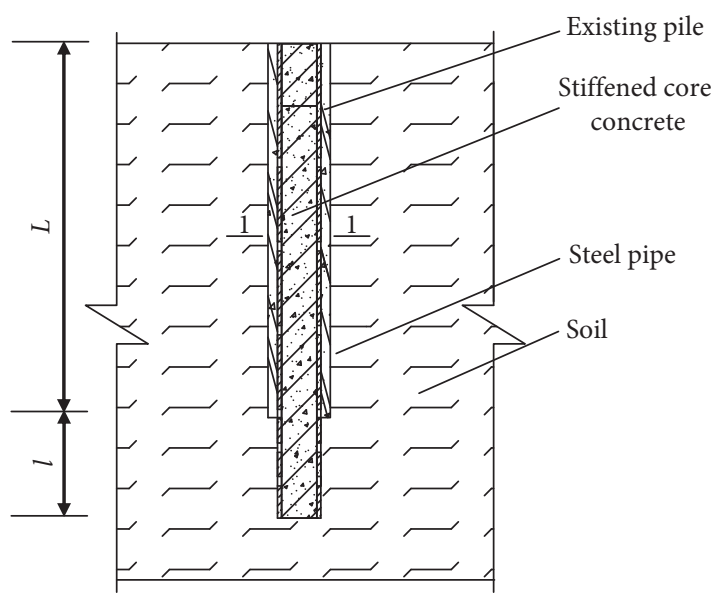

(a)

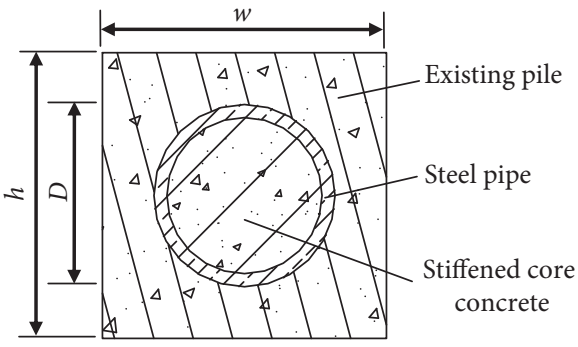

$1-1$

(the thickness of steel pipe is $t$ )

(b)

Figure 1: Cross section of concrete pile with lengthened core-concrete-filled steel pipe.

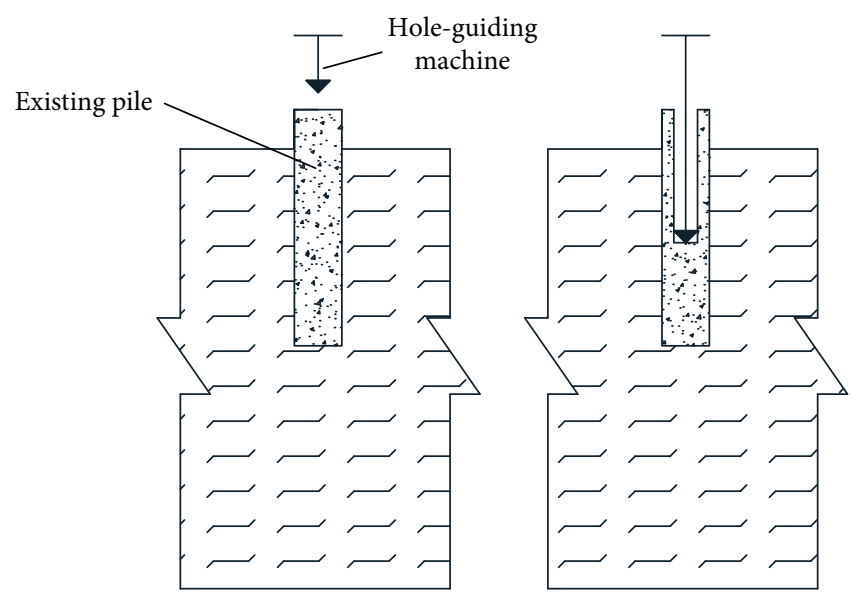

(a)

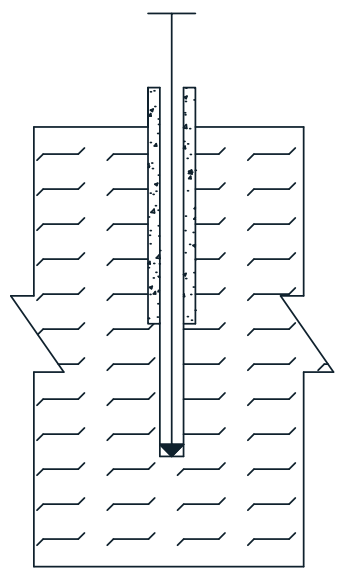

(b)

Figure 2: A sketch of hole-guiding in the existing concrete pile.

the proposed reinforced pile described in Section 2 through model tests.

3.1. Test Model Simplification. In order to facilitate the model test, the structure of the pile with an enhanced core is simplified as follows:

(1) The length and diameter of model pile are all reduced-scale, considering the condition of test site and equipment.

(2) The external concrete pile is simultaneously constructed with the core-concrete-filled steel tube, without postgrouting. Furthermore, the seepage hole of the steel tube is also ignored.

(3) The sampling piles are prefabricated and then embedded in the soil.

\subsection{Experimental Details}

3.2.1. Preparation of Sampling Piles. Six test piles, numbered, respectively, 0\#, 1\#, 2\#, 3\#, 4\#, and 4'\#, were constructed. Pile 0\# (also named the basic pile), with length $L=800 \mathrm{~mm}$ and cross-section dimensions $w \times h=$ $150 \mathrm{~mm} \times 150 \mathrm{~mm}$ (see Figure 3), was made of C30 concrete whose material parameters are listed in Table 1. Piles 1\# 4\# (see Figure 4) were all provided with lengthened steel pipe (the material constants are also reported in Table 1) through reserved holes in conventional pile of the same size with pile $0 \#$, and the lengthened size $l$ (see Figure 1) is, respectively, $200 \mathrm{~mm}, 300 \mathrm{~mm}, 400 \mathrm{~mm}$, and $500 \mathrm{~mm}$. The cross-section sizes of the steel pipe are $D \times t=$ $80 \mathrm{~mm} \times 4 \mathrm{~mm}$, and all the steel tubes were also filled with C30 concrete. Moreover, for further comparison, another conventional pile (without steel cube), i.e., piles 4’\#, with the same length as pile $4 \#$, and the same cross section and material as pile 0\#, was specially added (also see Figure 4). For clearance, Table 2 lists key geometries of all test piles.

3.2.2. Loading Devices. The vertical load was produced by heaped weight, generated through $150 \mathrm{~mm} \times 150 \mathrm{~mm}$ concrete blocks with an average weight of $7.9 \mathrm{~kg}$ each and is transferred 


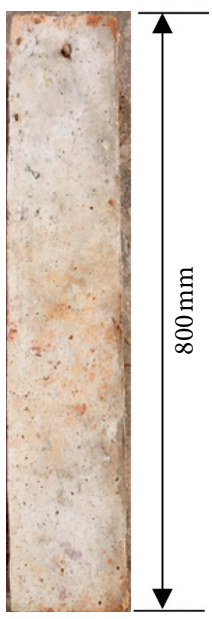

(a)

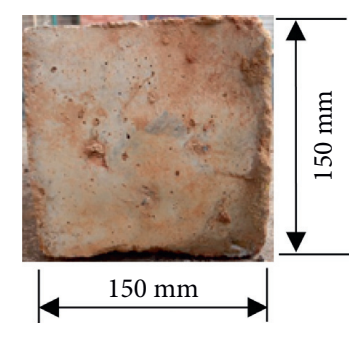

(b)

Figure 3: Pictures of test pile 0\#.

TABLE 1: Material parameters of concrete and steel pipe.

\begin{tabular}{lccc}
\hline Material & $\begin{array}{c}\text { Density } \\
\left(\mathrm{kg} / \mathrm{m}^{3}\right)\end{array}$ & $\begin{array}{c}\text { Young's modulus } \\
(\mathrm{MPa})\end{array}$ & Poisson's ratio \\
\hline Concrete & $2.4 \times 10^{3}$ & $3.0 \times 10^{4}$ & 0.2 \\
Steel pipe & $7.85 \times 10^{3}$ & $2.1 \times 10^{5}$ & 0.3 \\
\hline
\end{tabular}

to the pile through a $500 \mathrm{~mm} \times 500 \mathrm{~mm} \times 5 \mathrm{~mm}$ steel plate, fixed atop the pile by $8 \mathrm{~mm}$ diameter expansion screws (see Figure 5(a)) to ensure that the load is evenly applied along the axis of the pile. The horizontal loading was realized through a 10-ton hydraulic jack as shown in Figure 5(b).

3.2.3. Deformation Measuring Device. The vertical settlement displacement of the test pile was measured by two electronic digital dial indicators (see Figure 5(a)), with a measuring range of $0 \sim 20 \mathrm{~mm}$ and accuracy of $0.01 \mathrm{~mm}$, and symmetrically placed on both sides of the pile. The horizontal displacement was recorded by one dial indicator, the same type as in the vertical settlement tests and arranged $5 \mathrm{~cm}$ above the action surface of the horizontal force. To fix the dial indicators, a steel frame partially embedded in the soil was designed (also see Figure 5(a)).

To obtain the strain of the pile, BX120-10AA-type foil strain gages were pasted with quarter-bridge along the longitudinal direction of the pile body and connected through the conductor with the DH3818 strain gauge (see Figure 6).

Accordingly, take piles $0 \#$ and $3 \#$ for example, the measuring points are shown in Figure 7. Points A1 and A2 are on the pile top to record the vertical displacement, while point $\mathrm{A}$ is $50 \mathrm{~mm}$ below the pile top to capture the lateral displacement. Besides, points $\mathrm{B} \sim \mathrm{E}$ are set for strain measurement, where the distances of points B, C, and D to the ground level are, respectively, $0 \mathrm{~mm}, 300 \mathrm{~mm}$, and $600 \mathrm{~mm}$; as for point $\mathrm{E}$, it was placed at the center of the lengthened segment.

\subsubsection{Test Plan}

(1) Test Preparation. The test piles with strain gage pasted were firstly buried with their top $200 \mathrm{~mm}$ above the ground, and then the gap between the piles and around soil was filled and compacted; following, the steel frame was fixed (see Figure 5(a)). To make the soil denser, the loading tests were carried out 15 days later, after taking appropriate covering measures.

(2) Geotechnical Testing. To obtain the physical and mechanical index of the soil (e.g., water content, density, friction angle, and cohesion) around the pipe, geotechnical tests should be carried out. The samples were taken from soil around the pile $500 \mathrm{~mm}$ below the ground. Following [26], the water content was measured by drying method, the density was determined with ring knife technique, the friction angle and cohesion were obtained by direct shear test, and the limit water content was acquired through the liquid-plastic combined test. For simplicity, we ignore the detailed testing procedures.

(3) Vertical Compression Test under Static Load. One level of load (9 concrete blocks for each level of load) was added every hour to every pile, according to the fast maintenance loading method as required in [27]. After each level of loading, the settlement and strain of the pile body were recorded every 30 minutes. When the settlement of the pile top under a certain load was more than 5 times the previous level and the total settlement of the pile was more than $40 \mathrm{~mm}$, the loading test was terminated [27]. The final deformed results were also collected. Figure 8 shows two stages (loading level 1 and 5) of a vertically loaded pile.

(4) Horizontal Test under Static Load. In the horizontal static load test (see Figure 9), the slow maintenance loading method was adopted [27], with a loading increment of $0.05 \mathrm{MPa} / \mathrm{min}$. The distance between the action line of horizontal load and the pile top is $100 \mathrm{~mm}$. The horizontal 


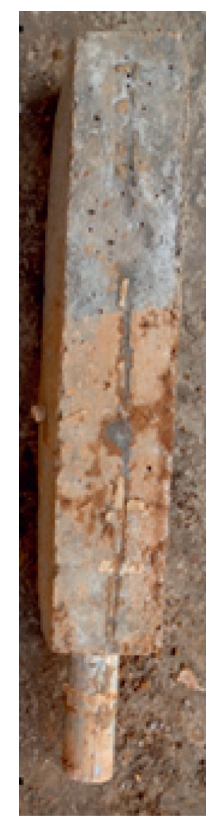

(a)

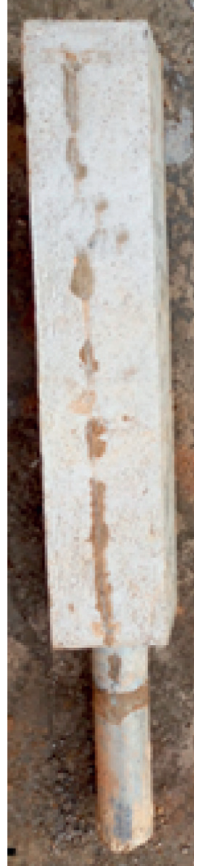

(b)

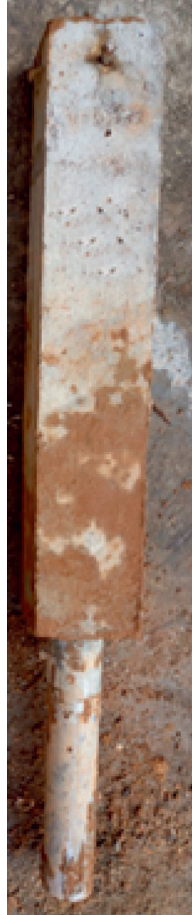

(c)

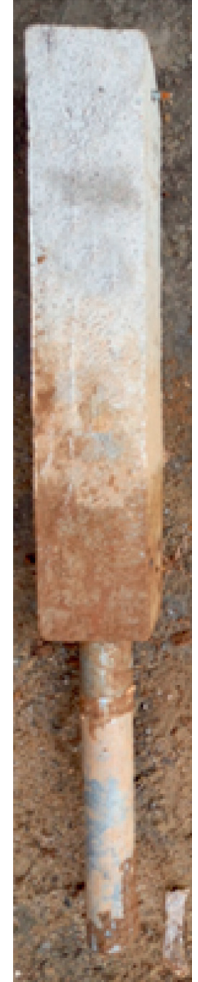

(d)

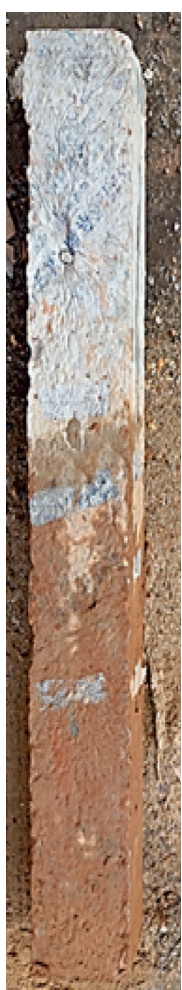

(e)

Figure 4: Pictures of test piles 1\# 4’\#: (a) 1\#, (b) 2\#, (c) 3\#, (d) 4\#, and (e) 4'\#.

TABLE 2: Length of the sampling piles.

\begin{tabular}{lcccccc}
\hline Pile number & $0 \#$ & $1 \#$ & $2 \#$ & $3 \#$ & $4 \#$ & \\
\hline$L(\mathrm{~mm})$ & 800 & 800 & 800 & 800 & 800 & 1300 \\
$l(\mathrm{~mm})$ & 0 & 200 & 300 & 400 & 500 & 0 \\
\hline
\end{tabular}

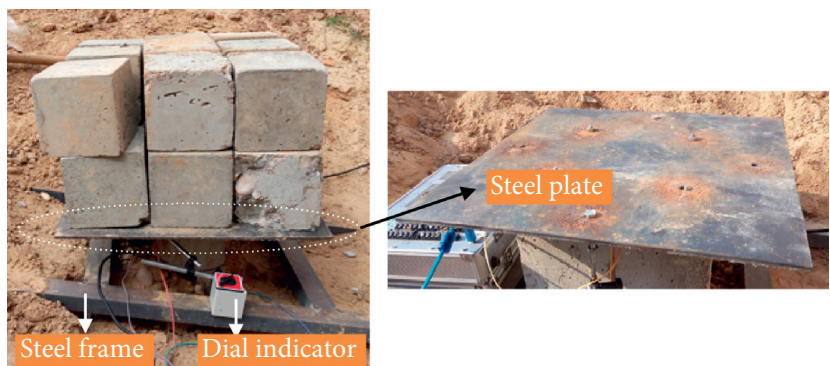

(a)

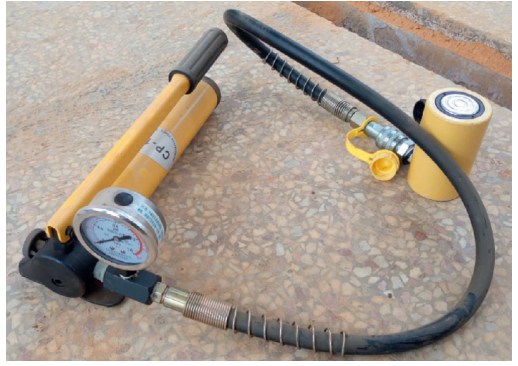

(b)

FIgURE 5: Devices for (a) vertical loading and (b) horizontal loading. 


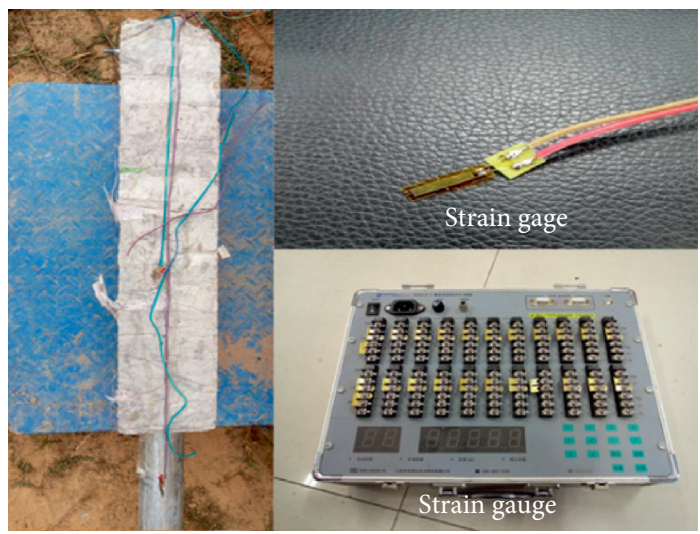

FIGURE 6: Deformation measuring device of the pile.

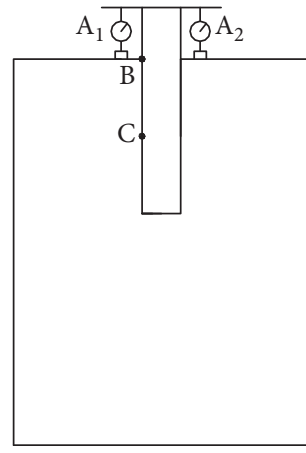

(a)

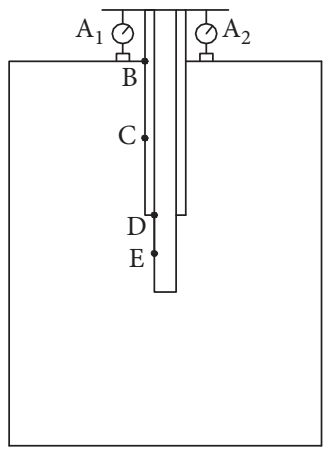

(c)

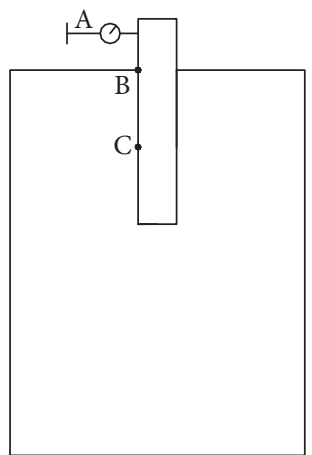

(b)

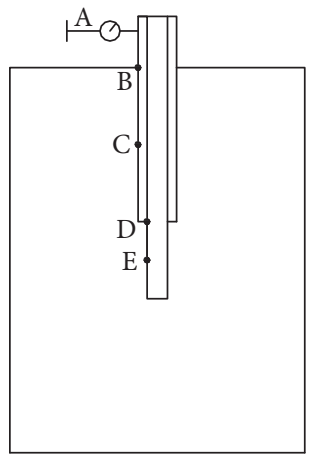

(d)

FIgURE 7: Layout of measuring points for (a) vertical deformation of pile 0\#, (b) lateral deformation of pile 0\#, (c) vertical deformation of pile $3 \#$, and (d) lateral deformation of pile $3 \#$.

displacement and the strain value of the pile were recorded every minute. When the horizontal displacement at the top of the pile exceeded $40 \mathrm{~mm}$, the loading test of the test pile was stopped [27], and the final deformation values were also gathered.

\subsection{Testing Results}

\subsubsection{Geotechnical Testing Results}

(1) Water Content Testing Results. The testing results from the drying method for two soil samples are listed in Table 3.
Since the water content difference of the two samples is less than $1 \%$ [26], we take the average of the two as the final water content, i.e., $w=25.3 \%$.

(2) Density Testing Results. The testing results with the ring knife technique for two soil samples are presented in Table 4. Seeing that the dry density difference of the two samples is less than $0.03 \mathrm{~g} / \mathrm{cm}^{3}$ [26], we take the average of the two as the final dry density, i.e., $\rho_{d}=1.51 \mathrm{~g} / \mathrm{cm}^{3}$.

(3) Direct Shear Testing Results. The relationship curve between shear strength and vertical pressure [26] is shown in 


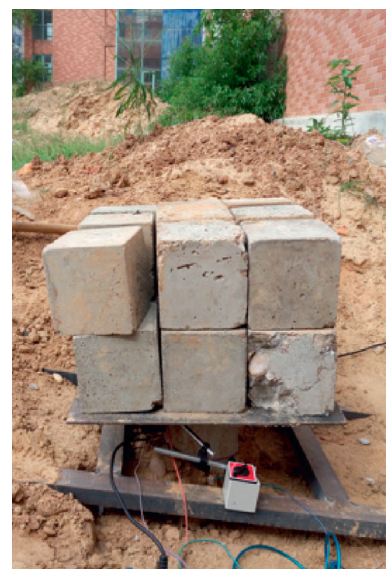

(a)

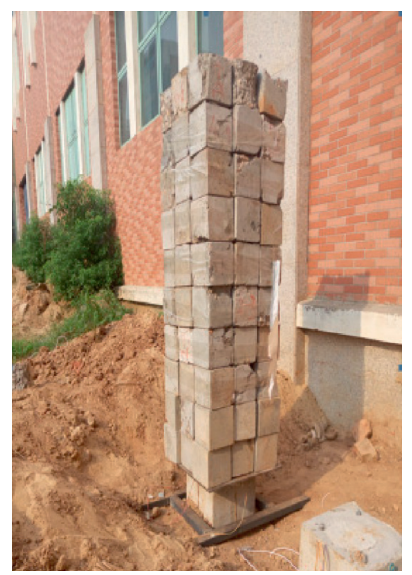

(b)

Figure 8: Vertical static load test of single pile.

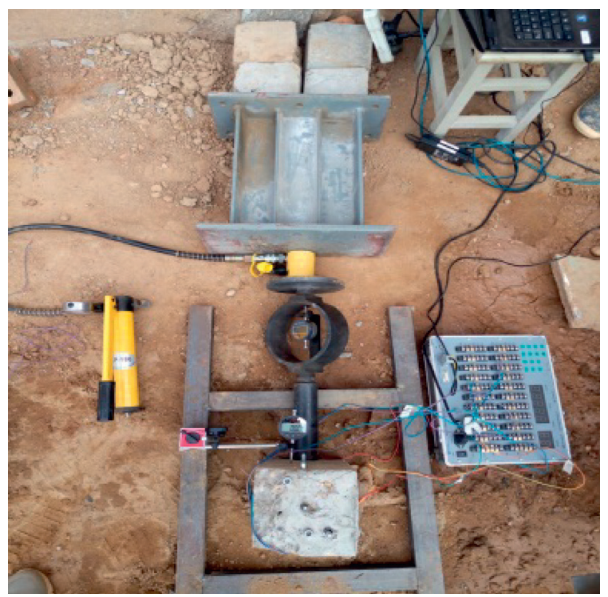

Figure 9: Horizontal static load test of single pile.

TABLE 3: Water content test data.

\begin{tabular}{lcccc}
\hline Sample & Weight of wet soil $(\mathrm{g})$ & Weight of dry soil $(\mathrm{g})$ & Water content $(\%)$ & Average water content $(\%)$ \\
\hline A & 50 & 39.97 & 25.1 & 25.3 \\
B & 50 & 39.84 & 25.5 & \\
\hline
\end{tabular}

Table 4: Density test data.

\begin{tabular}{lcccccc}
\hline Sample & Weight of wet soil $(\mathrm{g})$ & Volume of soil $\left(\mathrm{cm}^{3}\right)$ & Wet density $\left(\mathrm{g} / \mathrm{cm}^{3}\right)$ & Water content $(\%)$ & $\begin{array}{c}\text { Dry density } \\
\left(\mathrm{g} / \mathrm{cm}^{3}\right)\end{array}$ & $\begin{array}{c}\text { Average dry } \\
\text { density }(\%)\end{array}$ \\
\hline A & 114.12 & 60 & 1.90 & 25.4 & 1.52 \\
B & 112.20 & 60 & 1.87 & 25.0 & 1.50 \\
\hline
\end{tabular}

Figure 10, where the inclination angle of the approximated line gives the friction angle, i.e., $\varphi=21^{\circ}$, and the intercept of the ordinate represents the cohesion, namely, $c=11 \mathrm{kPa}$.
(4) Limit Water Content Testing Results. The double-logarithm-coordinate relationship curve between cone penetration depth and water content [27] is plotted in Figure 11. 


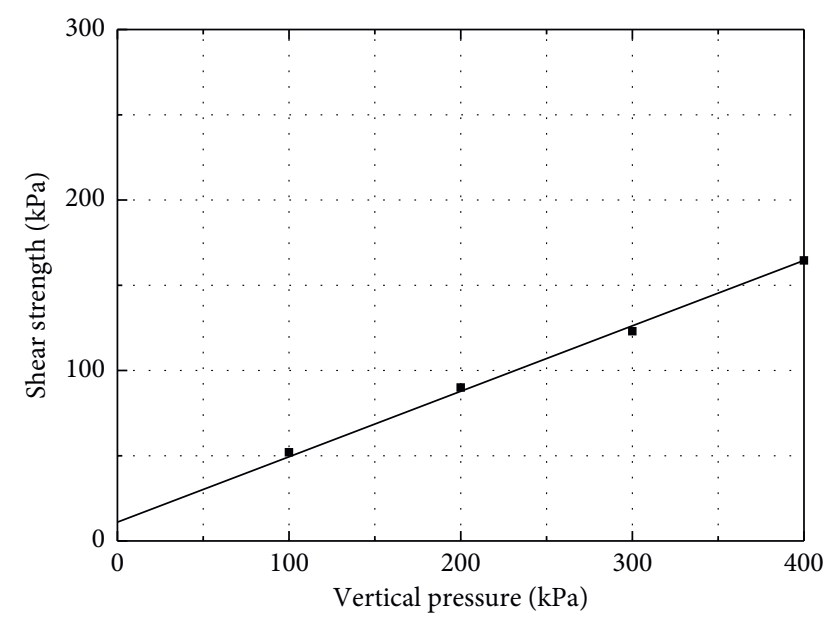

FIGURE 10: Shear strength of the soil under different vertical pressure.

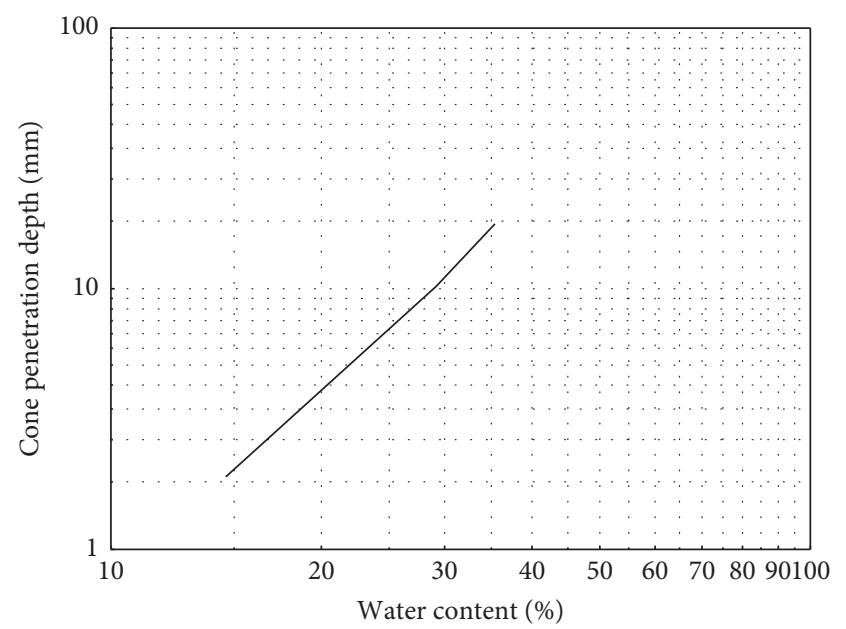

Figure 11: Cone penetration depth under different water content (log-log curve).

From this figure, the liquid limit $w_{l}$ (the water content when cone penetration depth is $17 \mathrm{~mm}$ [27]) is 37.0 and the plastic limit $w_{p}$ (the water content when cone penetration depth is $2 \mathrm{~mm}$ [27]) equals 18.6. Accordingly, the plastic index $I_{p}=w_{l}-w_{p}=18.4$. Based on [28], the sampling soil falls into low liquid limit clay.

\subsubsection{Vertical Compression Testing Results}

(1) Vertical Compressive Bearing Capacity. The load-displacement curves of all the test piles are shown in Figure 12 (the displacement takes the average values of points A1 and A2 in Figure 7), from which we can find that the corresponding curve of each pile has obvious inflection point and the total settlement of each pile is more than $40 \mathrm{~mm}$.

According to [27], the maximum vertical compressive bearing capacity of each pile takes the load value at the related inflection point. On these grounds, the distribution of the maximum bearing capacity of six piles is shown in

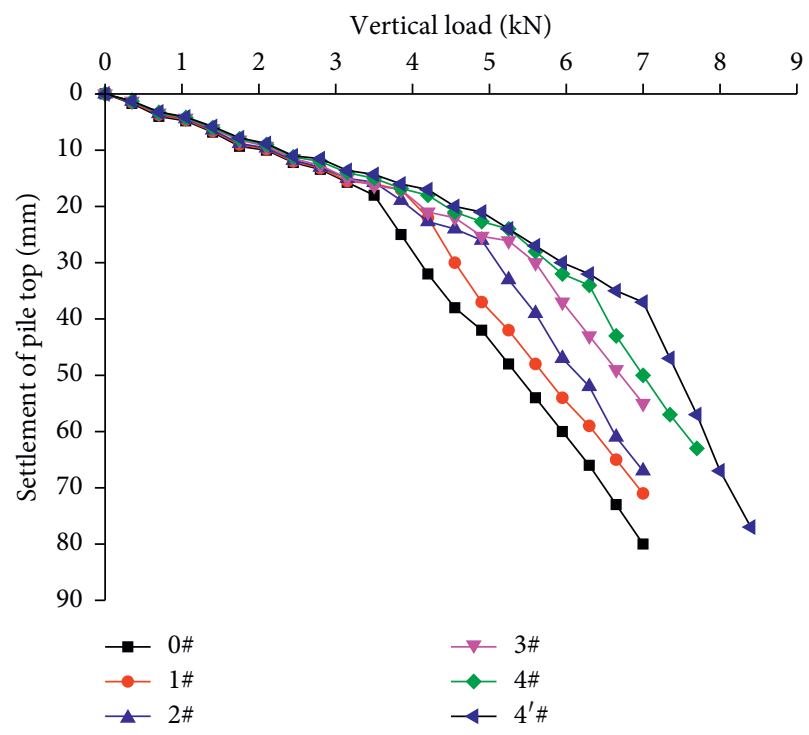

FIGURE 12: Settlement of pile top at different vertical load.

Figure 13. As seen in Figure 13, the maximum vertical bearing capacity of piles $1 \# \sim 4 \#$ is raised, respectively, by $18.3 \%, 37.4 \%, 55.7 \%$, and $77.3 \%$, compared to that of pile $0 \#$; while from Table 2, the lengthened part of the corresponding pile increases, respectively, by $25.0 \%, 37.5 \%, 50 \%$, and $62.5 \%$. Such outcome suggests that introducing a strong lengthened core can greatly improve the vertical bearing capacity, and the bearing capacity increases with the length of the strengthened core (filled steel tube). Besides, compared to pile $4 \#$, the maximum vertical bearing capacity of pile 4'\# is only increased by $6.3 \%$, although its contact area with the soil is $28.8 \%$ larger than that of pile $4 \#$. This demonstrates that although there is necking section in the lower part of pile $4 \#$, which may reduce the friction area of the pile side and affect the performance of the vertical compressive bearing capacity, it is not obvious compared with the conventional pile structure (say pile 4 '\#), indicating that the present design is reasonable.

(2) Axial Force. In the case of small loading, the deformation of pile body is approximately elastic. Accordingly, the axial force in the pile is computed by

$$
N=E A \varepsilon,
$$

where $E$ is Young's modulus, $A$ is the cross-section area, and $\varepsilon$ is the strain recorded by the strain gauge described in Section 3.2.

In view of the variable cross section and the effect of steel pipe, for piles $1 \# \sim 4 \#$, the compressive stiffness $E A$ in equation (1) is further calculated with [29]

$$
E A=E_{c} A_{c}+E_{s} A_{s}
$$

where $E_{c}$ and $E_{s}$ are, respectively, Young's modulus of concrete and steel tube. $A_{c}$ and $A_{s}$ denote, respectively, the cross-sectional area of concrete and steel tube.

With equation (1), the axial forces of each test pile were computed at various depths below the ground and the results 


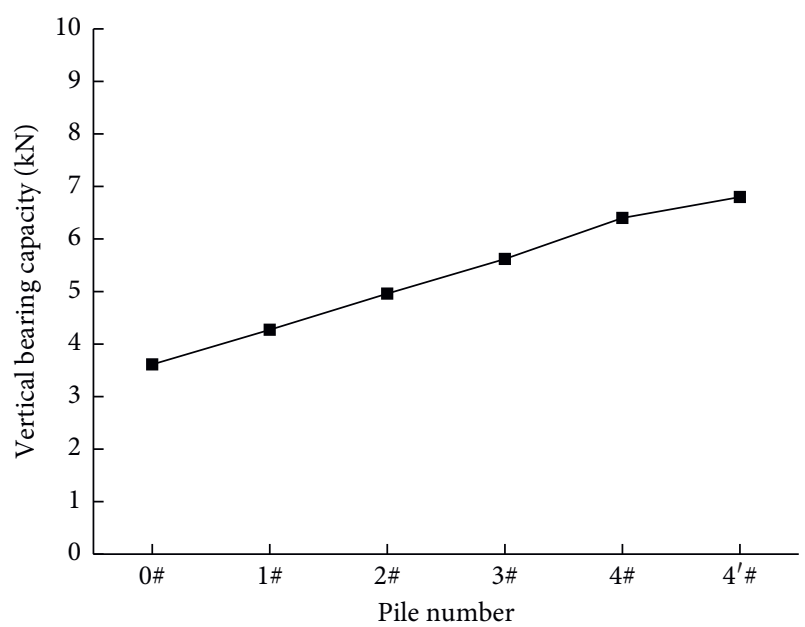

FIgURE 13: Vertical bearing capacity.

are plotted Figure 14, which shows that the axial force decreases at greater depths. These results corroborate with that of the maximum vertical bearing capacity test (shown in Figure 13), where the maximum vertical bearing capacity of piles $1 \# \sim 4 \#$ increases with the lengthened size (i.e., $l$ in Figure 1). Besides, the variation rules of axial forces of piles $1 \# \sim 4 \#$ with increasing depths are very similar, and value differences approximately equal to the differences in maximum vertical bearing capacity. The behaviors of piles $4 \#$ and 4'\# are quite different, mainly due to the change of the crosssection area, which alters the distribution of pile end and pile side resistance. Moreover, the axial force of pile $0 \#$ is similar to that of pile $2 \#$ at the same depth. This is because the length of the former is smaller than that of others, and the exertion of side friction resistance is therefore limited.

(3) Lateral Friction Resistance. From static equilibrium, the lateral friction resistance is expressed as

$$
q_{s}=\frac{N_{2}-N_{1}}{L_{0} L_{A}}
$$

where $N_{2}$ and $N_{1}$ are, respectively, the axial force of the upper and lower cross sections of the concerned pile segment. $L_{0}$ and $L_{A}$ represent, respectively, the length and perimeter of the very segment.

Through equation (3), the results of average lateral friction resistance at different depths are obtained and shown in Figure 15, which displays that the lateral friction resistance of all the piles changes along the depth. The values of piles $0 \#$ and 4' \# change slightly, whereas those of piles $1 \# \sim 4 \#$ vary considerably. This is because the related measuring points were arranged on the pile surface and the effect of stress concentration at the sudden change cross section was not fully considered. At the same time, at the lengthened part, the side friction decreases rapidly due to the sharply reduced cross section; however, the difference of friction between strengthened and conventional pile was not significant. For example, the side area of pile $4 \#$ was $28.8 \%$ less than that of pile 4 '\#, but the friction difference was only $17.8 \%$.

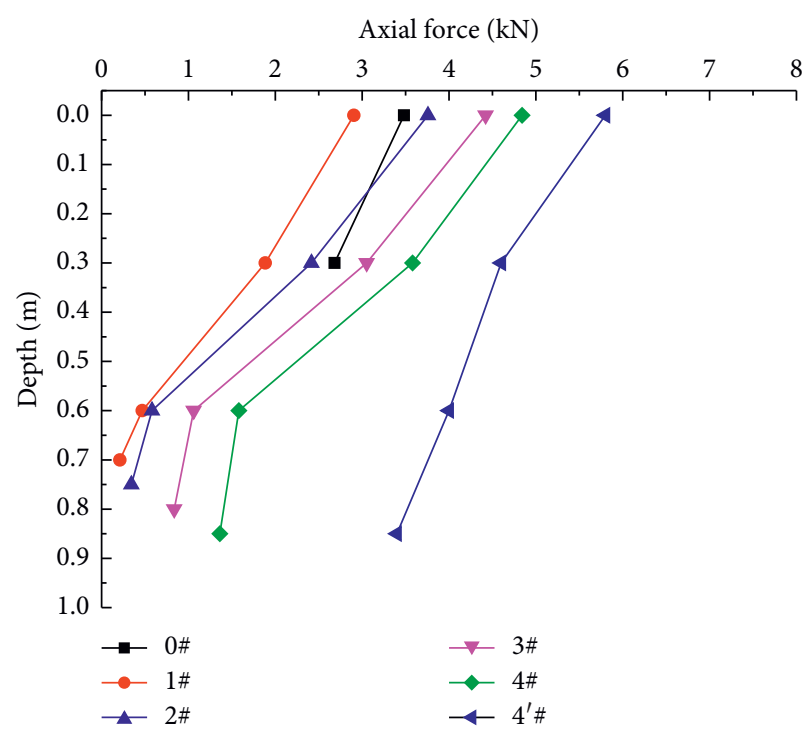

Figure 14: Axial force at different depths.

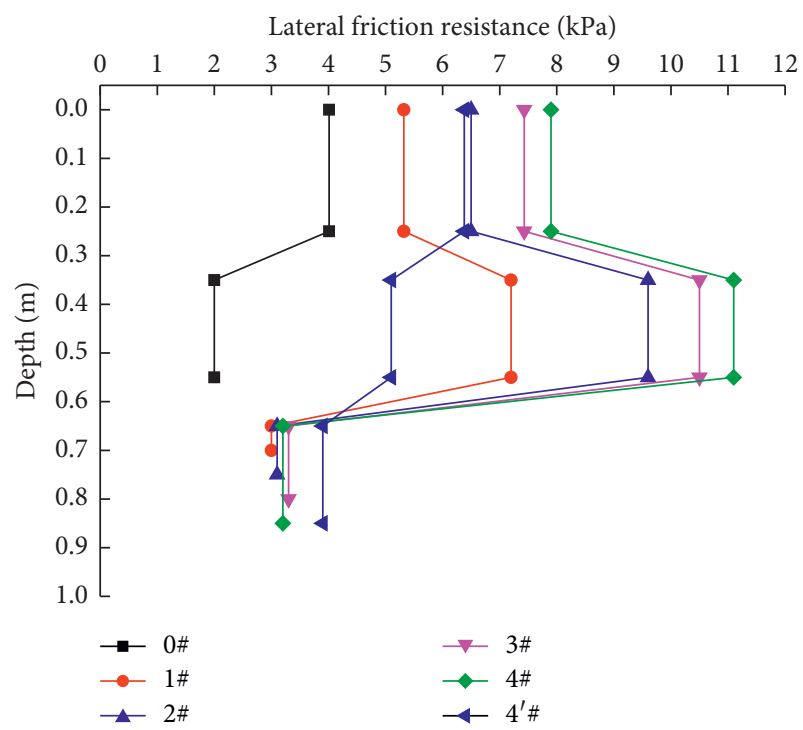

Figure 15: Average friction resistance at different depths.

\subsubsection{Horizontal Testing Results}

(1) Horizontal Bearing Capacity. The gradients of lateral displacement [27] at point A (see Figure 7) under different horizontal forces are shown in Figure 16. From Figure 16, we can observe that the inflection point of pile $0 \#$ is not apparent and the slope is large, suggesting rigid short pile failure. Pile 4'\# has a distinct inflection point, with low slope at first followed by a steep increase, suggesting elastic long pile failure. For piles $1 \# \sim 4 \#$, the displacement gradient increases rapidly after the load reaches the maximum horizontal bearing capacity. This rapid increase is because the stiffness of the pile is much greater than that of the soil around the pile, and the soil was damaged first under the action of a large horizontal force. 


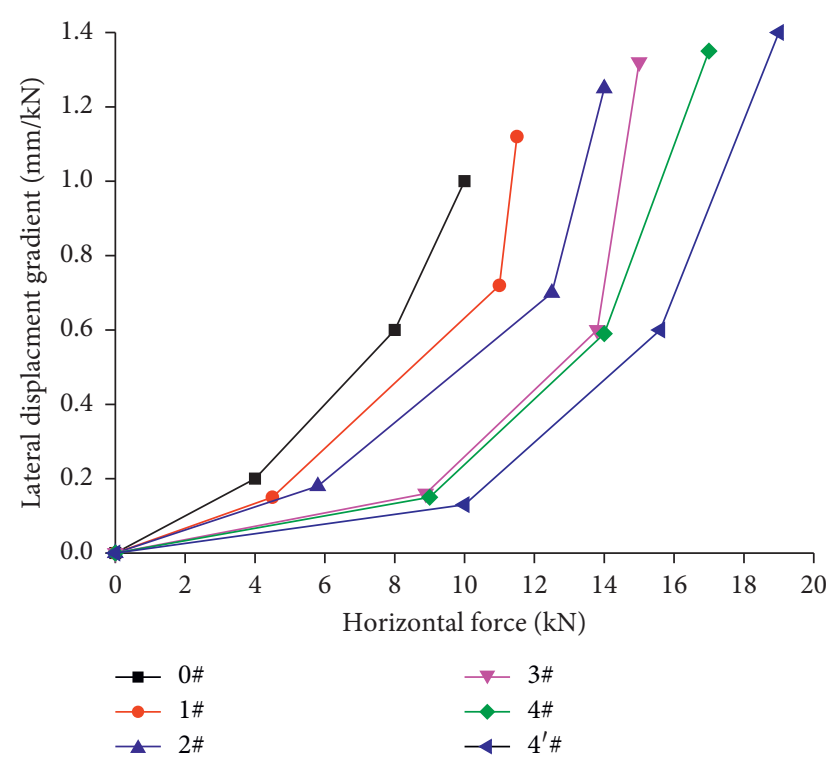

Figure 16: Lateral displacement gradient at point A under different horizontal force.

Furthermore, according to [27], the second inflection point of the corresponding curve in Figure 16 gives the horizontal ultimate bearing capacity, which is illustrated in Figure 17. It can be seen that the ultimate horizontal bearing capacity does not have the same linear growth trend as the vertical compressive bearing capacity in Figure 13. At piles $3 \#$ and $4 \#$, the slope of the curve slows down and the inflection point appears. This phenomenon may be used to determine the range of lengthened size.

Bending Moment. The bending moment of the pile is calculated through

$$
M=\frac{\sigma I}{y},
$$

where $\sigma$ is the stress computed by equation (1), $I$ is the moment of inertia for neutral axis, and $y$ is the vertical distance to the neutral axis.

Based on equation (4), bending moments at different depths for each test pile are shown in Figure 18, which indicates that the pile bending moment decreases gradually with the increased depth and tends to zero at the middle point of the length section, inferring that the pile segment below this point is unaffected by the lateral loading.

\section{Numerical Simulation of the Strengthened Pile}

In order to further reveal mechanical behaviors (e.g., the distribution of displacement and stress in the whole structure) of the proposed reinforced piles, this section presents corresponding finite element simulation based on the scale mode tests in Section 3 in the platform of PLAXIS 2D software.

4.1. Establishment of Simulation Model. To construct the simulation model, the following hypothesizes are adopted:

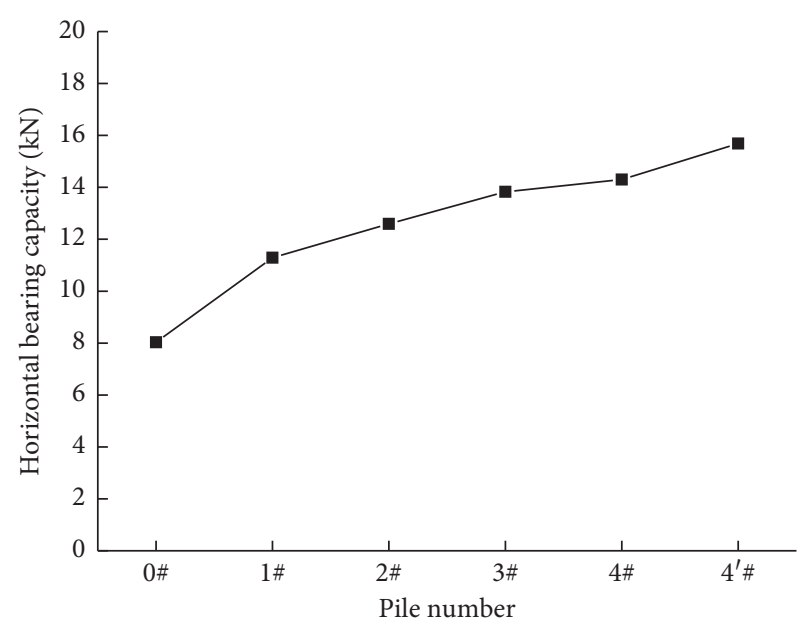

FIGURE 17: Horizontal ultimate bearing capacity of piles.

(1) The experimental model is simplified as a plane strain problem, with the influence of groundwater ignored.

(2) The soil, concrete, and steel tube were represented, respectively, by the ideal plastic Mohr-Coulomb model, the ideal nonporous linear elastic model, and the conventional plate model.

(3) The interface elements are set between the pile and soil, and the interface reduction strength parameter is taken to be 0.67 . Besides, there is no relative displacement between pile and steel tube.

(4) The vertical load acts on the pile top in the form of uniform force, and the concentrated horizontal load is applied on $100 \mathrm{~mm}$ below the pile top.

Based on the above assumptions, the simulation structure is illustrated in Figure 19, where all the boundary conditions and dimensions are labeled. When modeling, the physical and geometric parameters of the soil and pile body are the same as those in the laboratory tests. Accordingly in Figure $19, W=1000 \mathrm{~mm}, a=150 \mathrm{~mm}, \quad b=200 \mathrm{~mm}$, $c=600 \mathrm{~mm}$, and $D=80 \mathrm{~mm}$ (for piles $0 \#$ and $4^{\prime} \#$, $D=150 \mathrm{~mm}$ and steel tube should be ignored), the value of $l$ is listed in Table 2, and $H$ is summarized in Table 5.

The 15-node triangular element is used to discretize the domain. Take pile 3\# for example, the finite element model is shown in Figure 20. In order to compare to the lab tests, when the vertical settlement (under vertical loading) or horizontal displacement (under horizontal loading) of the pile top exceed $40 \mathrm{~mm}$, the loading stops. Moreover, the location of deformation observation points is the same as that in Figure 7. Accordingly, the initial stress field of the piles is generated.

\subsection{Simulation Results}

4.2.1. Bearing Capacity. According to finite element simulation, the results of the vertical and horizontal ultimate bearing capacity of piles are obtained and plotted, respectively, in Figures 21 and 22, together with the scale mode test 


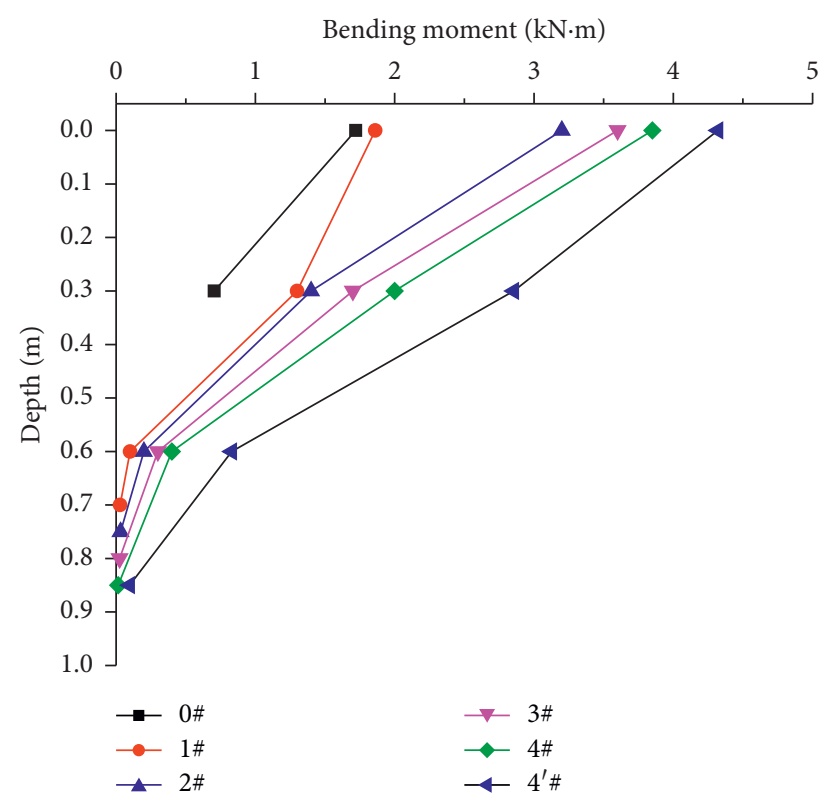

FIgURE 18: Bending moment of piles at varying depth.

TABle 5: The value of $H(\mathrm{~mm})$ in the simulation.

\begin{tabular}{lccccc}
\hline Pile 0\# & Pile 1\# & Pile 2\# & Pile 3\# & Pile 4\# & Pile 4'\# \\
\hline 1600 & 1800 & 1900 & 2000 & 2100 & 2100 \\
\hline
\end{tabular}

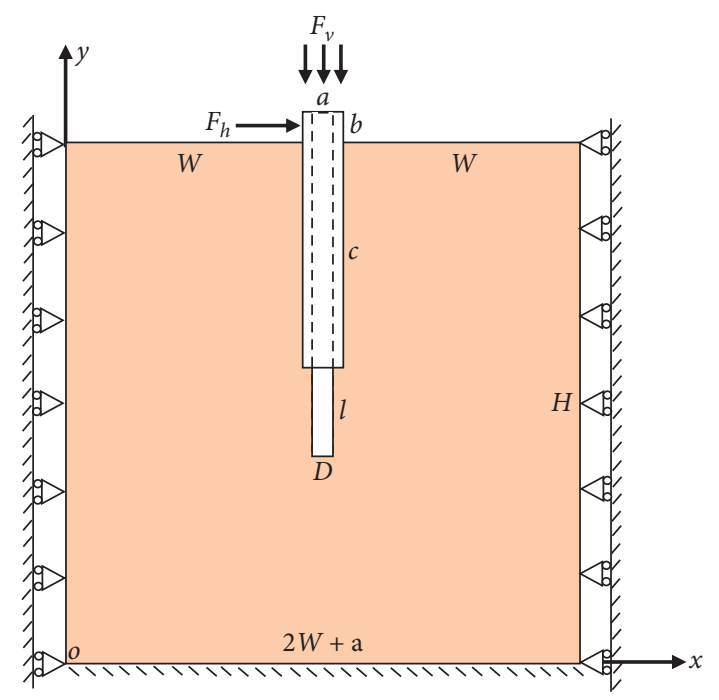

Figure 19: Simulation model.

values for comparison. From Figure 21, we can observe that the trend and values of two curves are very consistent, suggesting good corroboration between the experimental and simulation studies. Furthermore, from Figure 22, although at most cases the result of model test is higher than that of numerical simulation, the changing laws are also very similar, which again shows the agreement of these two approaches, considering the idealization of numerical model (e.g., in the simulation, the real 3D problem is simplified into
$2 \mathrm{D}$ case, and the practical heterogeneous soil around the pile body is assumed to be homogenous).

4.2.2. Displacement and Stress Distribution under Vertical Load. The displacement and stress distribution of the model at the completion stage of vertical loading are shown in Figures 23 and 24. We can find that the soil at the bottom of piles $0 \#$ and \# 4 has a large amount of compression, while that of the soil pile side is smaller and the influence range is limited. The stress distribution of the soil is mainly concentrated at the pile bottom, and the stress at the pile side is also very small. This suggests that under the vertical load, the conventional concrete pile transfers most of the top load to the pile bottom, and the soil pile side slips in a small range around the pile. The upper soil of piles $1 \# \sim 4 \#$ moves obviously with the pile position, and the influence range is very large. The soil stress has obvious changes around the pile body, which indicates there is strong friction between the pile and soil. The variable cross section of the pile bears part of the pressure at the pile end. The compression of the soil increases the displacement of the soil around the pile in the lengthened section and also reduces the compression and stress of the soil at the end of the pile.

4.2.3. Displacement and Stress Distribution under Horizontal Load. The displacement and stress distribution of the model at the completion stage of horizontal loading are illustrated in Figures 25 and 26. From these figures, we can view that pile $0 \#$ demonstrates overall lateral deformation, while the lateral deformation of piles $1 \# \sim 4 \#$ and 4 '\# pile is concentrated in a certain range below the ground, and the longer the pile is, the more obvious this effect is. This is because with the increase of pile length, the influence range of load decreases and the embedded mechanism of pile tip increases. However, we can see that the length of pile $1 \#$ is not much 


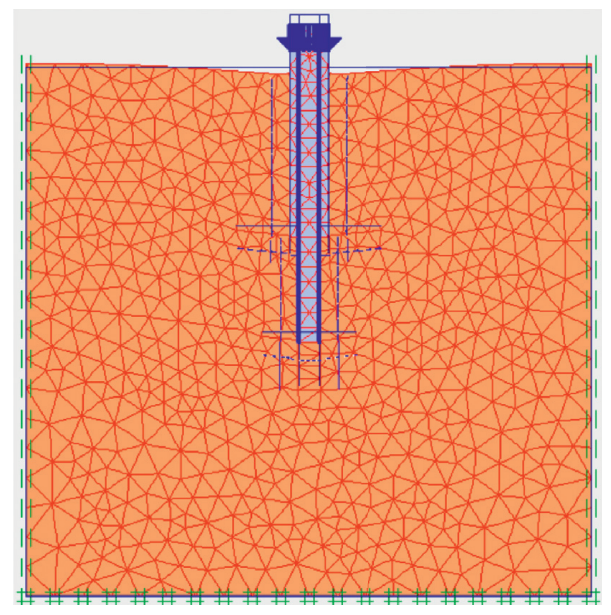

(a)

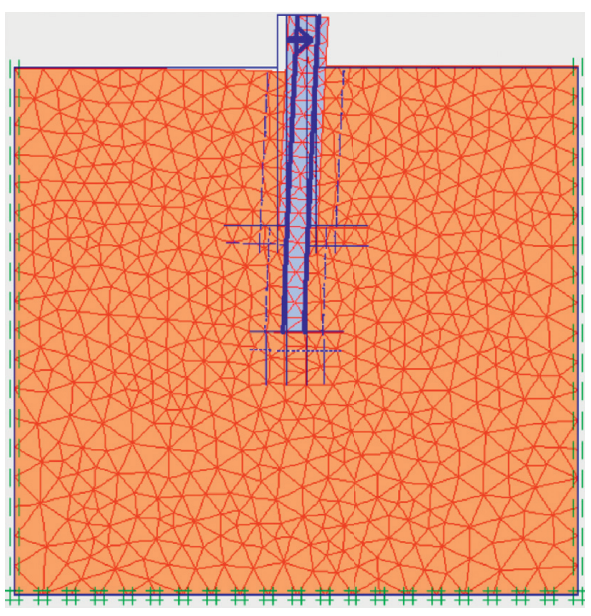

(b)

Figure 20: Finite element model of pile 3\#: (a) under vertical load and (b) under horizontal load.

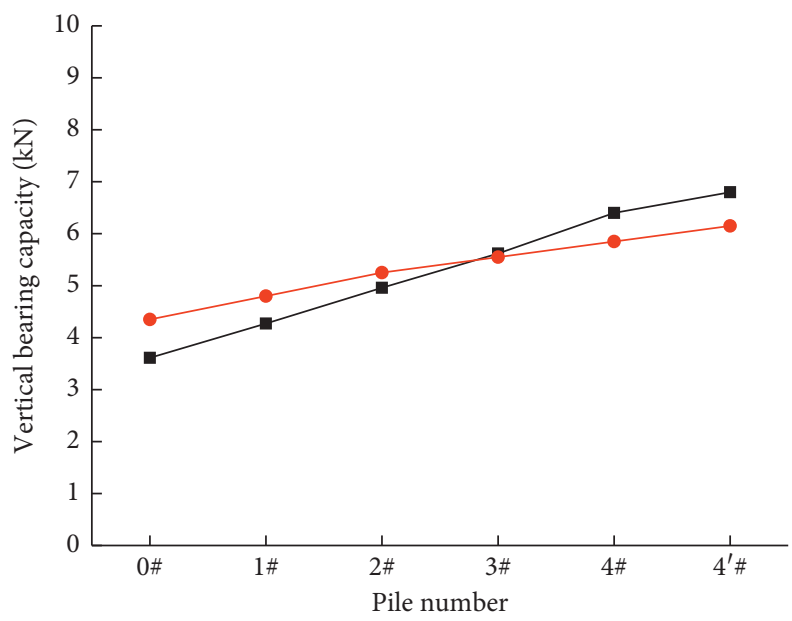

$\rightarrow$ Scale model test

$\rightarrow$ Numerical simulation

Figure 21: Vertical bearing capacity of piles.

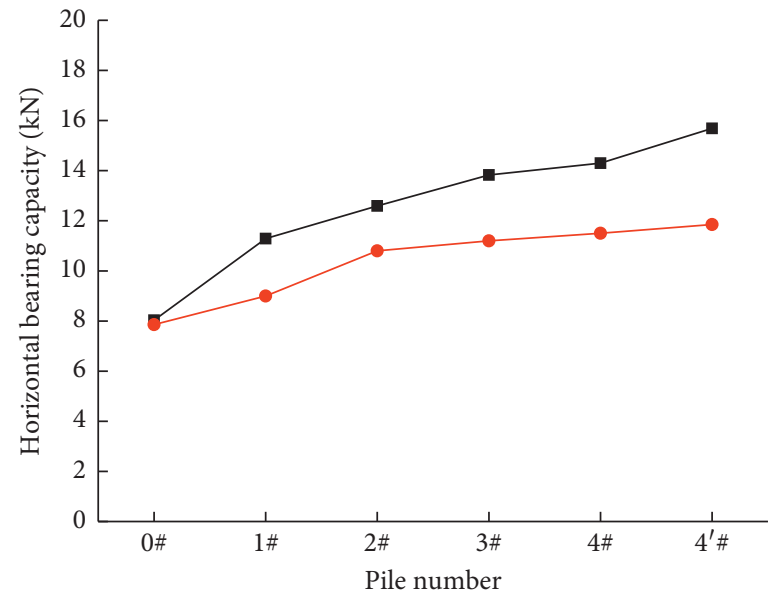

- Scale model test

$\longrightarrow$ Numerical simulation

FIGURE 22: Horizontal bearing capacity of piles. 


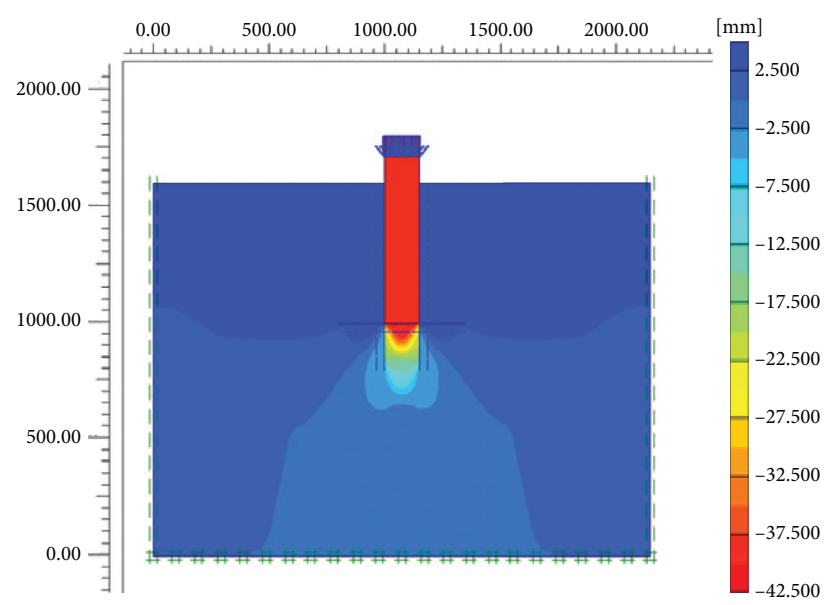

(a)

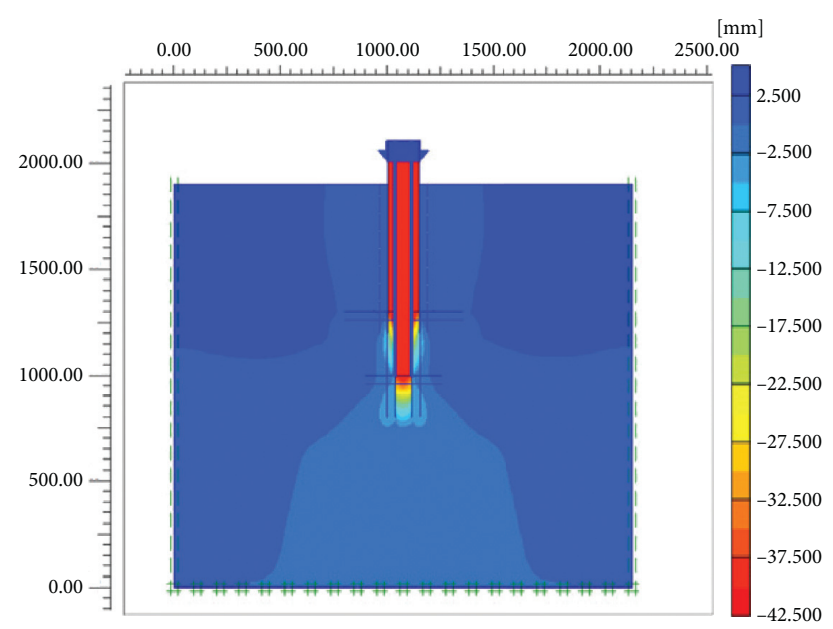

(c)

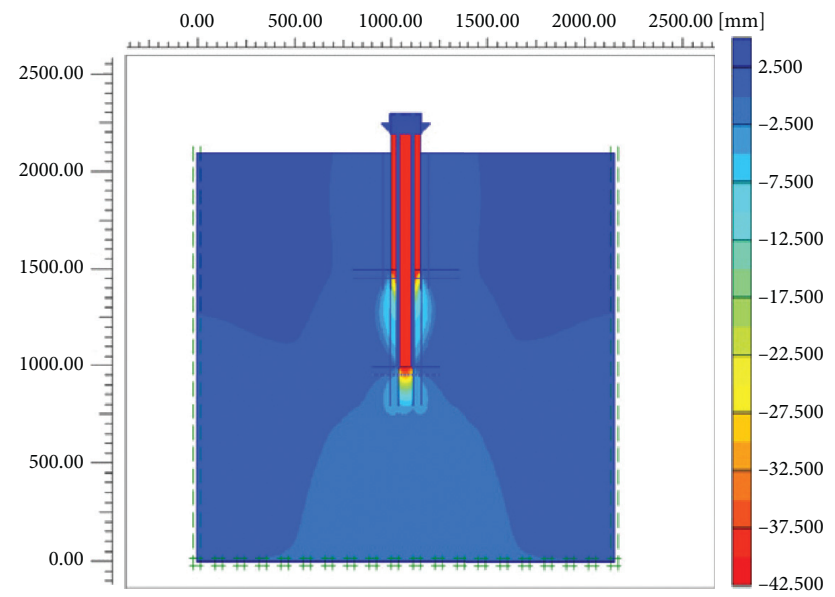

(e)

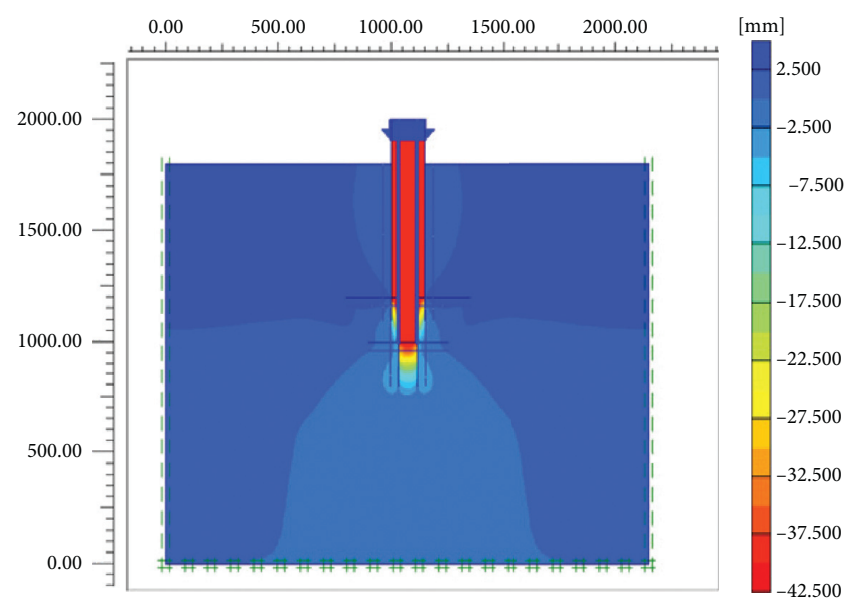

(b)

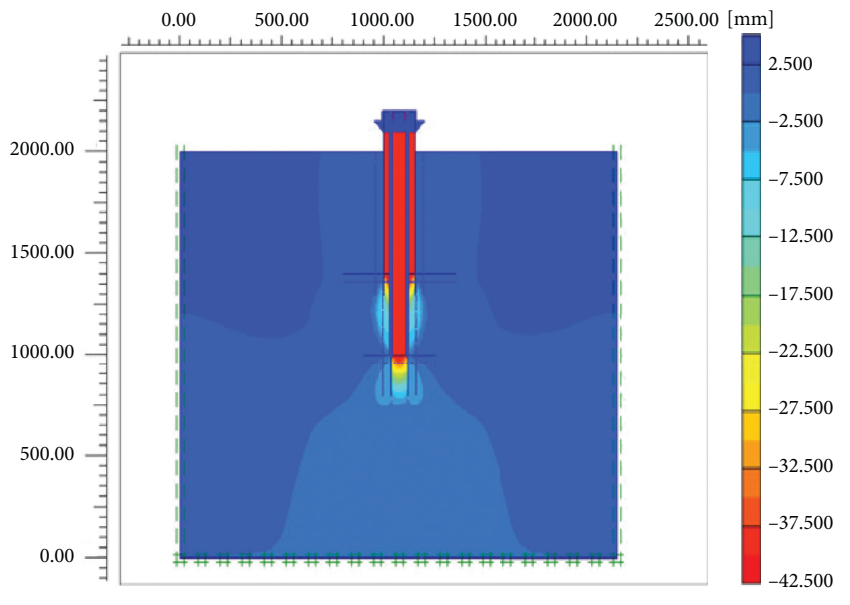

(d)

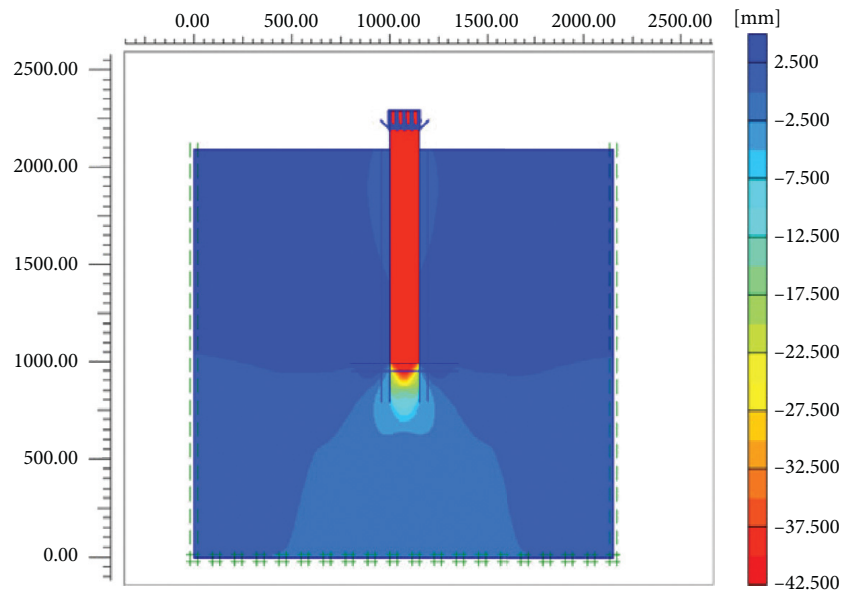

(f)

Figure 23: Displacement distribution at the completion stage of vertical loading for pile (a) 0\#, (b) 1\#, (c) 2\#, (d) 3\#, (e) 4\#, and (f) 4\#.

longer than that of pile $0 \#$, but the displacement contour of soil has obvious shrinkage. The stress contour of the model is not symmetrical, which is mainly reflected in the larger stress in the passive zone of the soil. The stress distribution in the passive zone of piles $0 \#$ and $4 \#$ is more uniform, and the maximum point is concentrated at the bottom of the pile, while the soil stress in the growing section of piles $1 \# \sim 4 \#$ is larger, which can more effectively resist the overturning 


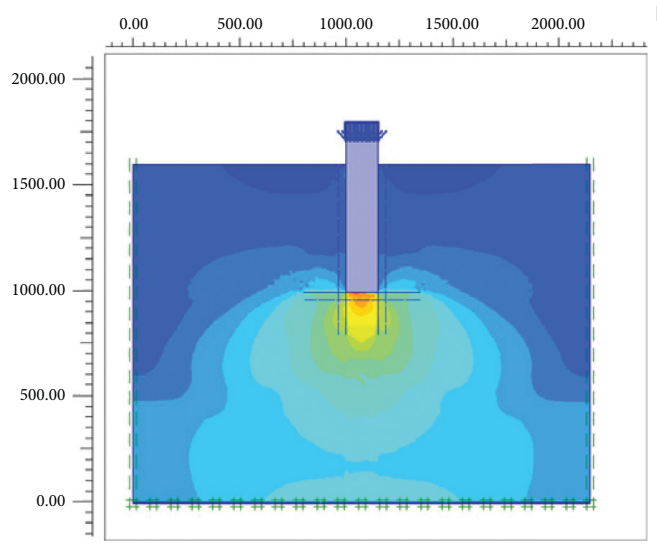

(a)

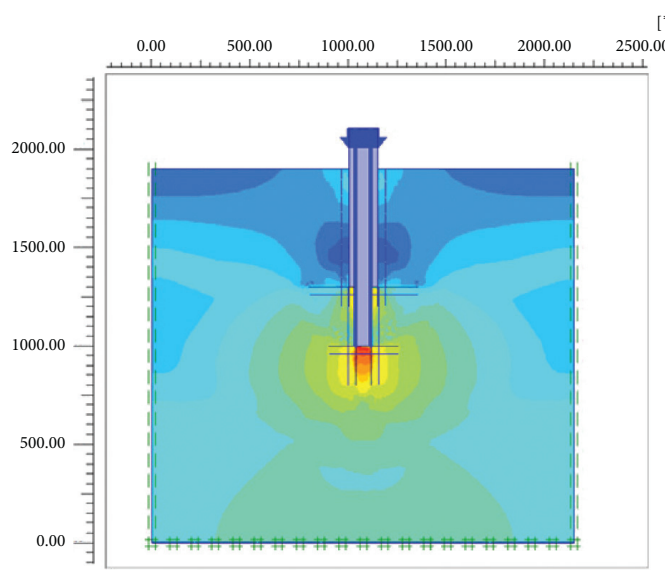

(c)

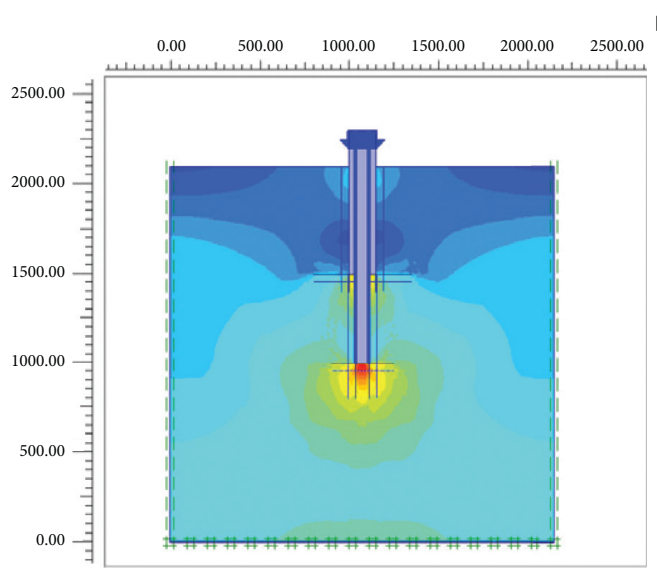

(e)

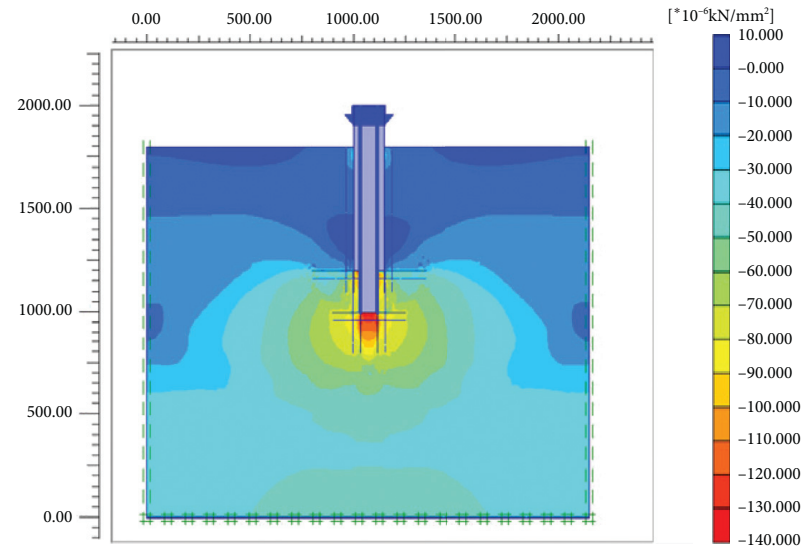

(b)

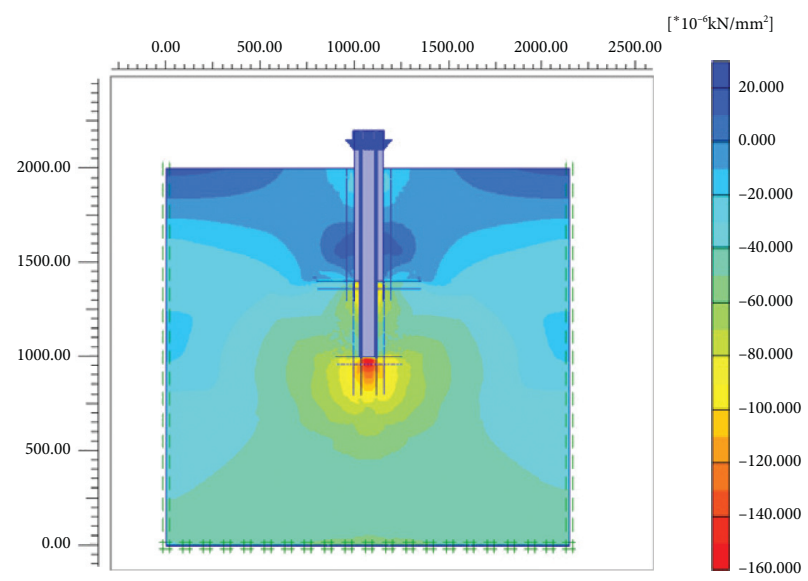

(d)

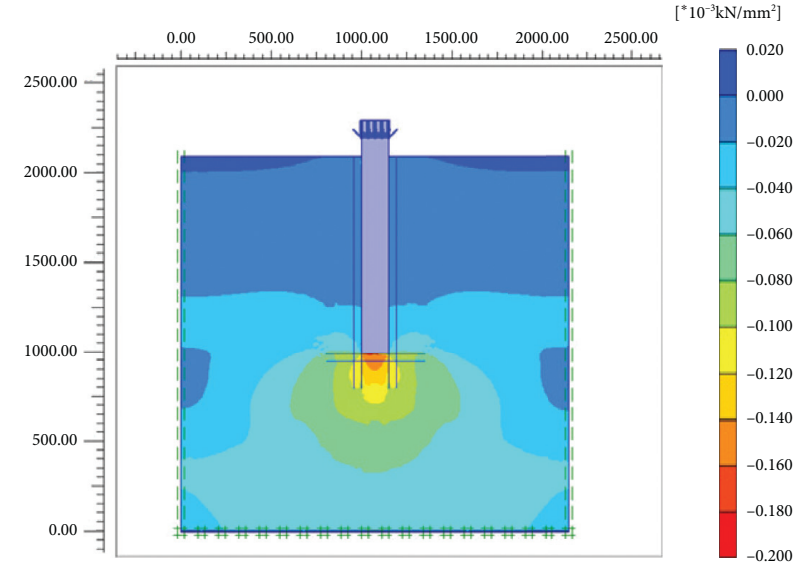

(f)

FiguRE 24: Stress distribution at the completion stage of vertical loading for pile (a) 0\#, (b) 1\#, (c) 2\#, (d) 3\#, (e) 4\#, and (f) 4\#\#. 


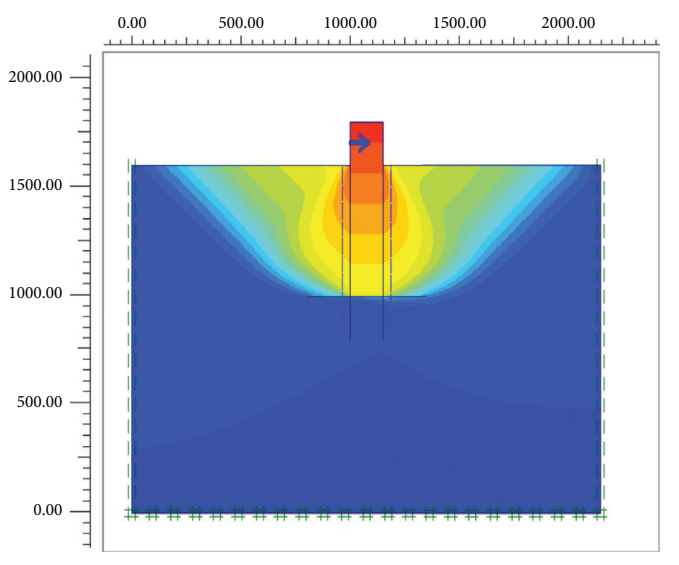

(a)

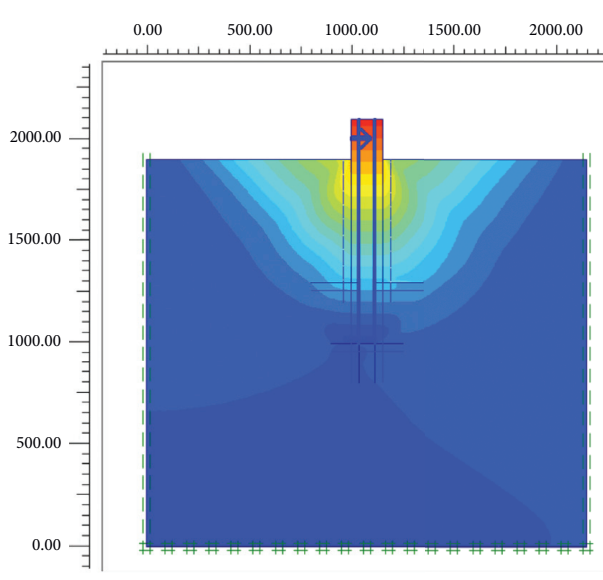

(c)

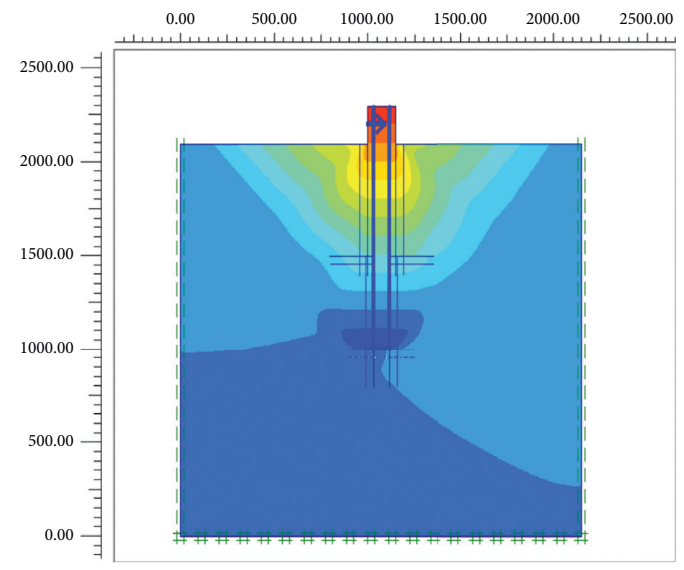

(e)
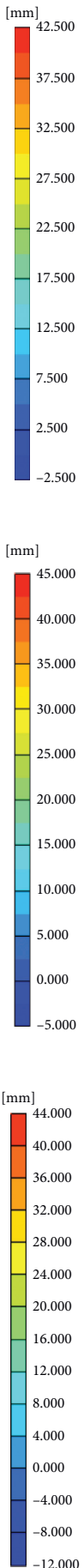

$-12.000$

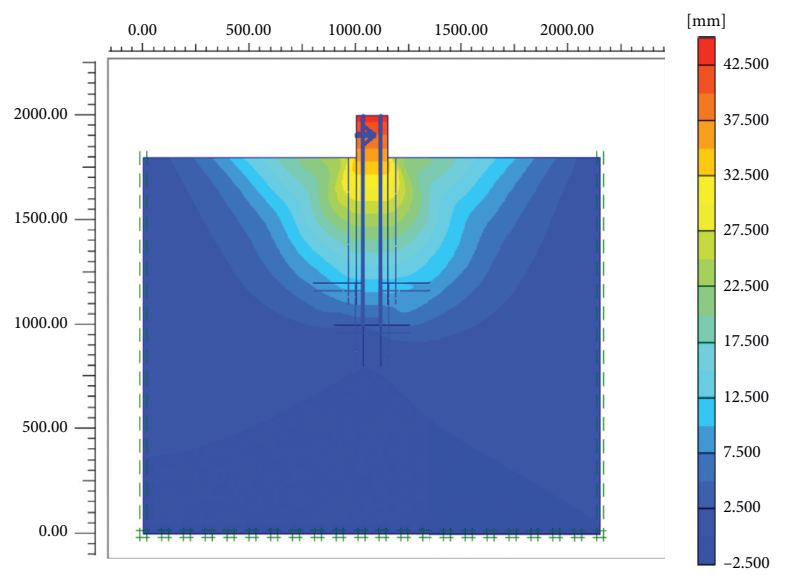

(b)

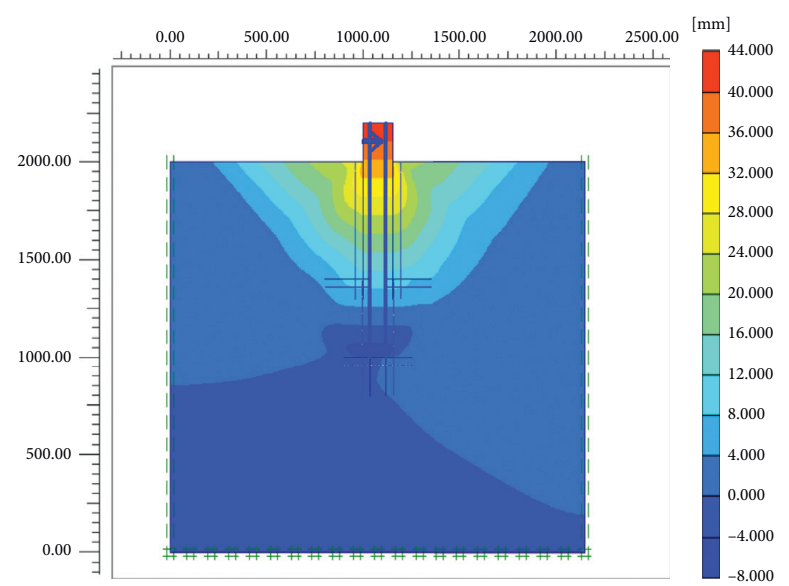

(d)

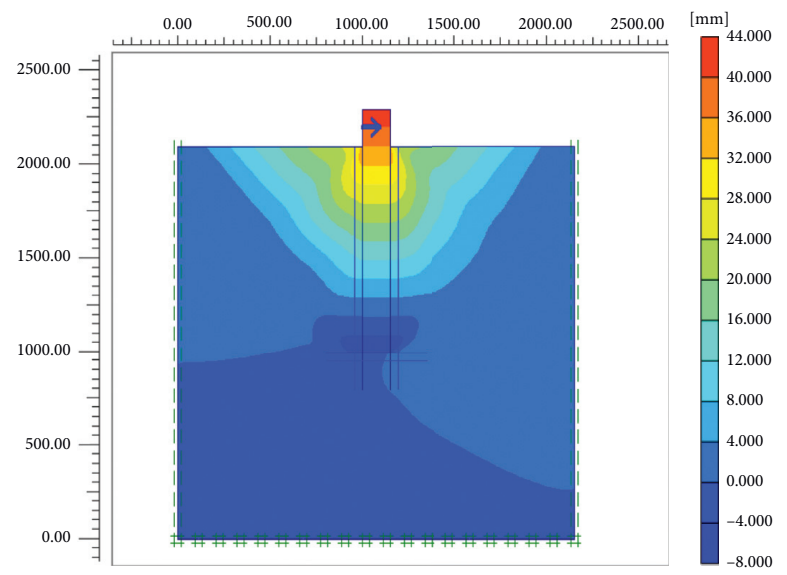

(f)

FIGURE 25: Displacement distribution at the completion stage of horizontal loading for pile (a) 0\#, (b) 1\#, (c) 2\#, (d) 3\#, (e) 4\#, and (f) 4'\#. 


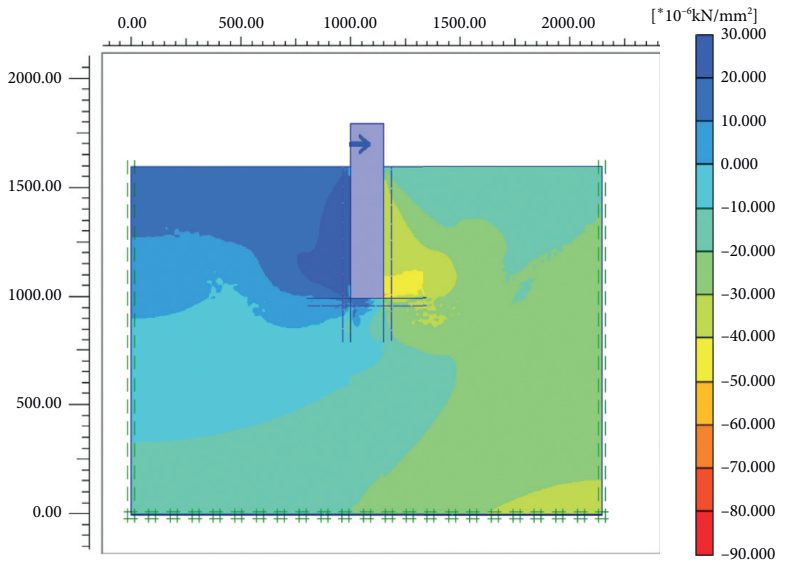

(a)

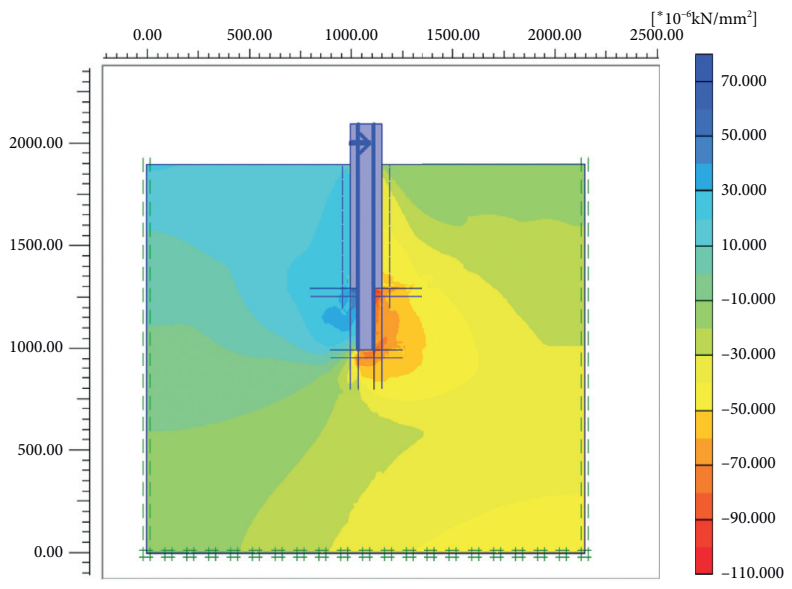

(c)

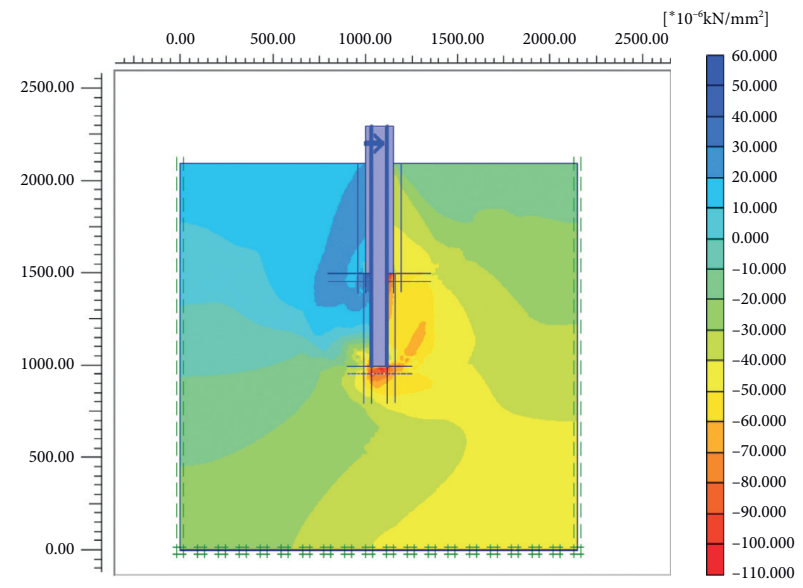

(e)

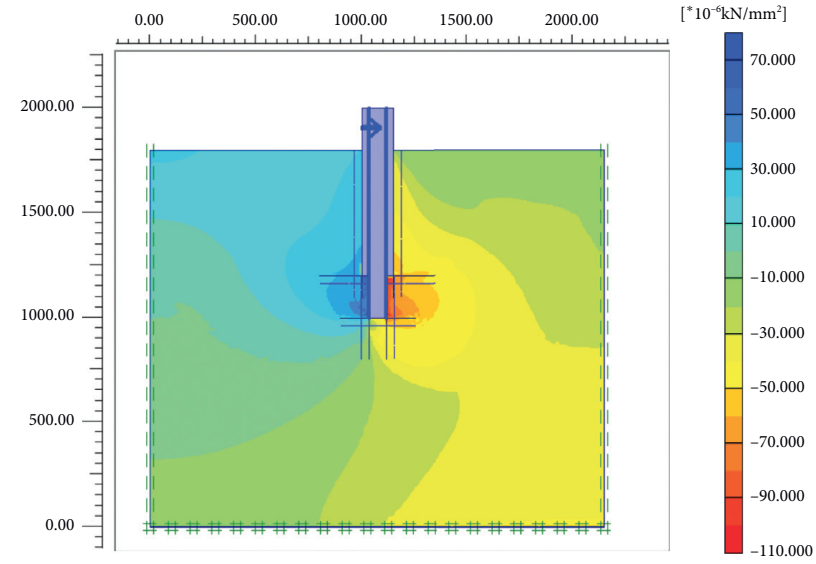

(b)

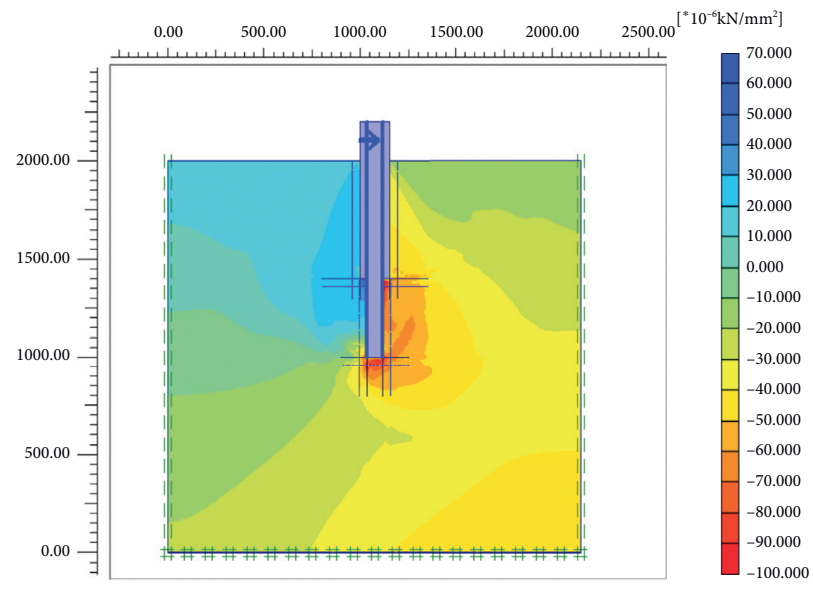

(d)

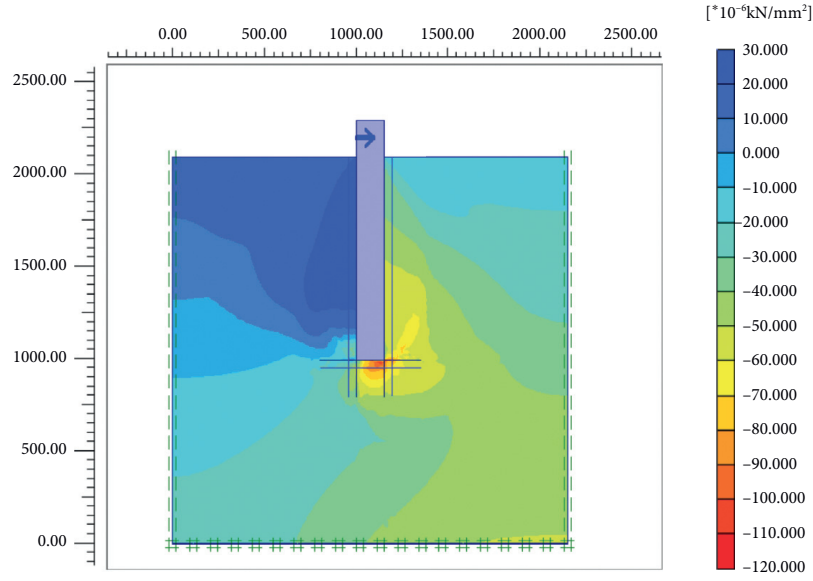

(f)

Figure 26: Stress distribution at the completion stage of horizontal loading for pile (a) 0\#, (b) 1\#, (c) 2\#, (d) 3\#, (e) 4\#, and (f) 4’\#. 
moment. Therefore, the proposed reinforced style enhances the pile-soil occlusion.

\section{Conclusions}

In this paper, a concrete pile reinforced by strengthened steel tube was proposed. Both scale model tests and numerical simulations were carried out to examine the mechanical behaviors of the presented pile (e.g., the vertical and horizontal bearing capacity, axial force, lateral friction resistance, and bending moment). Through the above studies, the following conclusions can be drawn:

(1) The designed pile with lengthened strength core meets the requirements of existing pile retention and bearing capacity improvement.

(2) The vertical compressive bearing capacity of the pile increases linearly with increased length of the strength core. The axial force of the pile is smaller than that of the conventional concrete pile, and the lengthened section can share the axial force of the foundation pile and improve the stress distribution of the pile body.

(3) The lateral bearing capacity of the pile with lengthened strength core is obviously higher than that of the conventional pile, but when the lengthened proportion exceeds $50 \%$ of the length of the original pile, the increase in lateral bearing capacity slows down.

(4) The simulation results show that the friction force between pile and soil can be better exerted by the pile with lengthened strength core. When bearing the horizontal load on top of the pile, the stress in the passive zone of the pile is concentrated at the pile bottom and the variable cross section, and there is obvious stress spread phenomenon in the lengthened section.

\section{Data Availability}

The raw/processed data required to reproduce these findings can be obtained by contacting with the first author through e-mail: hshyu@nchu.edu.cn.

\section{Conflicts of Interest}

The authors declare that they have no conflicts of interest.

\section{Acknowledgments}

This work was supported by the National Natural Science Foundation of China (grant no. 52068054).

\section{References}

[1] I. D. Psychas, M. Schauer, J.-U. Böhrnsen et al., "Detection of defective pile geometries using a coupled FEM/SBFEM approach and an ant colony classification algorithm," Acta Mechanica, vol. 227, no. 5, pp. 1279-1291, 2016.
[2] J. Wu, K. Wang, and M. H. El Naggar, "Half-space dynamic soil model excited by known longitudinal vibration of a defective pile," Computers and Geotechnics, vol. 112, pp. 403-412, 2019.

[3] J. Wu, M. H. El Naggar, K. Wang, and X. Liu, “Analytical study of employing low-strain lateral pile integrity test on a defective extended pile shaft," Journal of Engineering Mechanics, vol. 146, no. 9, pp. 04020103-04020112, 2020.

[4] X. Liu, M. H. El Naggar, K. H. Wang, and J. T. Wu, "Vertical response analysis at multi-points on defective pile in layered soil and its application," Soil Dynamics and Earthquake Engineering, vol. 139, pp. 106538 1-106538 17, 2020.

[5] D. Kim, J. Kim, and S. Jeong, "Estimation of axial stiffness on existing and reinforcing piles in vertical extension remodeled buildings," Engineering Structures, vol. 199, pp. 1-12, 2019.

[6] S. Jeong and D. Kim, "Estimation of design axial stiffness of reinforcing piles in vertical extension remodelling process using numerical computation," Engineering Structures, vol. 214, pp. 1-12, 2020.

[7] O. D. Neto, R. P. D. Cunha, P. J. R. De Albuquerque, J. R. Garcia, and O. F. D. Junior, "Experimental and numerical analyses of a deep foundation containing a single defective pile," Latin American Journal of Solids and Structures, vol. 17, no. 3, pp. e270 1-e270 15, 2020.

[8] L. Wang, B. He, Y. Hong, Z. Guo, and L. Li, "Field tests of the lateral monotonic and cyclic performance of jetgrouting-reinforced cast-in-place piles," Journal of Geotechnical and Geoenvironmental Engineering, vol. 141, no. 5, pp. 06015001-06015008, 2015.

[9] H. J. Li, L. Y. Tong, S. Y. Liu, Q. F. Gu, and L. Zhu, "Experimental study on lateral bearing behavior of post-grouting super-long bored pile," Journal of Building Structures, vol. 37, no. 6, pp. 204-211, 2016.

[10] G. L. Dai and Z. H. Wan, "Enhanced mechanism and loadsettlement relationship of post-grouting piles," Chinese Journal of Geotechnical Engineering, vol. 39, no. 12, pp. 2235-2244, 2017.

[11] H. Lin, M. T. Suleiman, H. M. Jabbour, D. G. Brown, and E. Kavazanjian, "Enhancing the axial compression response of pervious concrete ground improvement piles using biogrouting," Journal of Geotechnical and Geoenvironmental Engineering, vol. 142, no. 10, pp. 04016045-04016112, 2016.

[12] H. Lin, M. T. Suleiman, H. M. Jabbour, and D. G. Brown, "Bio-grouting to enhance axial pull-out response of pervious concrete ground improvement piles," Canadian Geotechnical Journal, vol. 55, no. 1, pp. 119-130, 2018.

[13] L. W. Ren, Y. B. Deng, and W. D. Guo, "Analysis of vertically loaded jet-grout-pile-strengthened piles of expanded crosssection," Proceedings of the Institution of Civil EngineersGeotechnical Engineering, vol. 171, no. 3, pp. 252-266, 2018.

[14] G. Ozden and C. T. Akdag, "Lateral load response of steel fiber reinforced concrete model piles in cohesionless soil," Construction and Building Materials, vol. 23, no. 2, pp. 785-794, 2009.

[15] C. T. Akdag and G. Özden, "Nonlinear behavior of reinforced concrete (RC) and steel fiber added RC (WS-SFRC) model piles in medium dense sand," Construction and Building Materials, vol. 48, no. 1, pp. 464-472, 2013.

[16] R. Sen, G. Mullins, and M. Shahawy, "Fiber-reinforced polymer repair and strengthening of structurally deficient piles," Transportation Research Record, vol. 2028, no. 1, pp. 221-230, 2007.

[17] J. Aguilar, D. Winters, R. Sen, G. Mullins, and M. Stokes, "Fiber-reinforced polymer pile repair incorporating cathodic 
protection," Transportation Research Record: Journal of the Transportation Research Board, vol. 2150, no. 1, pp. 111-118, 2010.

[18] A. H. Ali, A. Gouda, H. M. Mohamed, M. H. Rabie, and B. Benmokrane, "Nonlinear finite elements modeling and experiments of FRP-reinforced concrete piles under shear loads," Structures, vol. 28, no. 1, pp. 106-119, 2020.

[19] O. Chaallal, M. Shahawy, and M. Hassan, "CFRP repair and strengthening of structurally deficient piles: design issues and field application," Journal of Composites for Construction, vol. 10 , no. 1 , pp. 26-34, 2006.

[20] T. C. Lin, C. H. Jeng, C. Y. Wang, and T. H. Jou, "Repair of corroded prestressed concrete piles of harbor landing stages," ACI Structural Journal, vol. 109, no. 5, pp. 715-725, 2012.

[21] M. Rambo-Roddenberry, K. Joshi, S. Fallaha et al., "Construction, strength, and driving performance of carbon-fiber-reinforced polymer prestressed concrete piles," PCI Journal, vol. 61, no. 4, pp. 24-37, 2016.

[22] N. Zhuang, H. Dong, Y. Zhou, and D. Chen, "Cracking behavior of reinforced concrete piles externally bonded with carbon fiber reinforced polymer in a marine environment," Construction and Building Materials, vol. 190, no. 1, pp. 1154-1162, 2018.

[23] P. Wu, Y. Guo, D. Zhu, W. Jin, Z. Zhang, and R. Liang, "Flexural performances of prestressed high strength concrete piles reinforced with hybrid GFRP and steel bars," Marine Georesources \& Geotechnology, vol. 38, no. 5, pp. 518-526, 2020.

[24] M. Murugan, K. Muthukkumaran, and C. Natarajan, "FRPstrengthened RC piles I: piles under static lateral loads," Journal of Performance of Constructed Facilities, vol. 31, no. 3, pp. 04017003-04017014, 2017.

[25] M. Murugan, K. Muthukkumaran, and C. Natarajan, "FRPstrengthened RC piles II: piles under cyclic lateral loads," Journal of Performance of Constructed Facilities, vol. 31, no. 3, pp. 04017004-04017006, 2017.

[26] Ministry of Housing and Urban Rural Development of the People's Republic of China, Standard for Geotechnical Testing Method (GB/T 50123-2019), China Planning Press, Beijing, China, 2019.

[27] Ministry of Housing and Urban Rural Development of the People's Republic of China, Technical Code for Detection of Building Foundation Piles (JGJ 106-2014), China Architecture \& Building Press, Beijing, China, 2014.

[28] Ministry of Water Resources of the People's Republic of China, Classification Standard of Engineering Soil (GB/T 15145-2007), China Planning Press, Beijing, China, 2008.

[29] Harbin Institute of Technology and China Academy of Building Research, Technical Specification for Concrete-Filled Steel Tubular Structures (CECS28: 2012), China Planning Press, Beijing, China, 2012. 